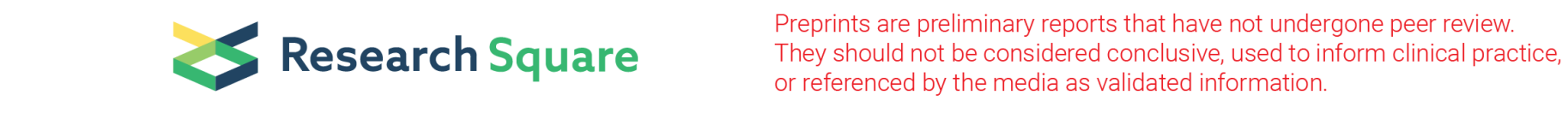

\title{
Survey On The application of Deep Learning in Internet of Things (IOT)
}

shabnam shadroo ( $\nabla$ shadrooshabnam@gmail.com )

Islamic Azad University https://orcid.org/0000-0002-0094-0372

\section{Amir Masoud Rahmani}

Islamic Azad University

\section{Ali Rezaee \\ Islamic Azad University}

\section{Research Article}

Keywords: Internet of things, deep learning, systematic mapping, systematic literature review

Posted Date: April 5th, 2021

DOI: https://doi.org/10.21203/rs.3.rs-271839/v1

License: (c) (i) This work is licensed under a Creative Commons Attribution 4.0 International License. Read Full License 


\section{Abstract}

The Internet of Things (IOT) is a network of physical instruments, software, sensors that all are connected to the Internet. The loT produces massive data, where, this enormous volume of data allows the use of deep learning algorithms (DLAs). Recently, the increase of the large body of data and their availability has been one of the main reasons for paying attention to this issue. Further, the recent upgrade of the hardware boosting the computational power has resulted in the utilize of deep learning alongside the loT. Therefore, the purpose of the present research is to review the relevant conference and journal articles in loT and deep learning from 2012 to July 2019. To review the publications, a composition of Systematic Mapping and systematic literature review has been employed for creating a survey paper. Accordingly, some questions have been raised; to answer which, 32 articles have been investigated. The papers have been categorized into four sections including a focus on data, network, computing environment, application with each being examined, and analyzed. This article would be beneficial for researchers who want to investigate the field of deep learning and loT.

\section{Introduction}

The devices such as mobile, transportation, and home facilities can be utilized as a data-processing device and connected to an IoT network. This network that is a new phenomenon in recent technology can remotely control these devices [1, 2, 3]. Many loT applications can be found in a variety of domains. The main component in many of these programs is the intelligent learning method for prediction, pattern recognition, data mining, or data analysis. Out of the numerous strategies of machine learning, researchers have observed the extensive use of deep learning in numerous loT programs in later a long time. The technologies of deep learning as well as loT have been among the 3 main technologies announced in 2017 at the Gartner/ITxpo 2016 symposium. This extensive advertising in deep learning highlights the reality that traditional machine learning methods could not respond to the new analytical required of the loT. Instead, the loT system requires artificial intelligence techniques and data analytic methods suited to the hierarchical process of loT data generation and data management $[4,5,6]$.

Deep learning refers to the improvement of machine learning models utilized to learn a hierarchical representation of data. A general term for a set of neural networks with multi-layer architecture is deep neural networks which present how neural networks with many layers can successfully create the required representational structures for deep learning. Learning algorithms can be used as supervised or unsupervised to adjust the weights of these networks. Deep learning methods transform the input data hierarchically and through a multi-layer model into a set of features, which are finally handed over to a classifier for classification [7].

In applications where there are so many situations, a deep model may be utilized to estimate the rates of operation (for example, how to operate well in a certain situation). Those systems that combine deep learning with reinforcement have been considered to be in their early stages, but recently in some applications (such as video games), competitive results have been developed. Further, it is expected that supervised and unsupervised learning approaches improve in the future [8]. loT programs can advantage from the decision-making processes for learning aim. Such as, within the case of residential services, it is possible to consider the area estimation as a decision-making method where a software agent decides the nearest point to a particular purpose or its precise area.

In this research, the publications in the scope of the loT and its combination with deep learning would be systematically studied. As far as we know, so far any systematic review has been not conducted on this subject, so this article would be beneficial for relevant researchers. In the first part of the article, some questions are raised and according to the proposed methods, the available articles are compared with each other based on the four categories. In the end, questions of the study would be answered.

This research is arranged in four sections. Section 2 presents methodology and questions. Section 3 considers the comparison of the major investigations in the article and answers to the questions appointed in the article are given in Section 4. Ultimately, Section 5 concludes the research. 


\section{Methodology}

This study reviews a systematic combination of loT with deep learning models. The study employed the steps discussed in the Cruz-Benito research [9] and other studies $[10,11,12,13,14,15,16,17,4]$. We will discuss the combination of SLR[1] and SMS[2] methods and explain the steps provided in this research.

\section{2-1. Research Questions (RQs)}

Articles that are systematically published provide a general overview based on the category presented to the reader. In these types of articles, they examine the studies available in the subject matter and report the coverage of the subject in the publications. Further, by studying published articles in the form of SMS, they can find the current challenges in the subject, where these articles can greatly help the researchers to present their new ideas. For the systematic review of articles, we should first ask questions and then look for their answers in the valid articles. The questions raised in this article are as follows:

RQ1: What are the most appropriate and common tools, simulators, and datasets in the Internet of Things and Deep Learning field?

By answering this question, the growth of articles in this field and the up-to-datedness of this field can be proven.

RQ2: What are the most appropriate and common tools, simulators, and datasets in the Internet of Things and Deep Learning field?

By replying to this question, researchers will be informed of the tools, datasets, and simulators applied in these fields.

RQ3: Which one of the deep learning models and platforms have been utilized more in the loT?

By answering this question, the most widely used models and platforms can easily be recognized.

RQ4: What are the most important challenges of deep learning along with loT?

We introduce the existing challenges to newbies researching in the DL and loT area by answering this question.

RQ5: What are the open issues of deep learning along with loT?

By answering the above questions, further investigations will show new paths of deep learning-loT.

\section{2-2. Database}

The focus of this research is primarily on reviewing research-based databases, and the authors assumed that the books written on these domains have been employed in these articles. Hence, we have not studied the books describing the issue in this article.

The research-based databases employed in this survey are:

- ACM[3] Library [67].

-IEEE[4] Xplore Digital Library[68].

- Elsevier [69].

- Springer Link [70].

- Wiley Online Library [71].

\section{2-3. Selection Criteria and Non-Selection Criteria}


The criteria applied in this research have been previously used in [4]. We study the journals and conference papers published in the English language from 2012 to July 2019 in our systematic review. The selection and non-selection criteria for articles are described in Table 1.

Table. 1. Selection Criteria and Non-Selection Criteria [4]

\begin{tabular}{|l|}
\hline Selection Criteria \\
Articles whose focus is "deep learning "and ("loT" or "internet of things") \\
Articles that have been published between 2012 and July 2019. \\
\hline Non-selection Criteria \\
Books and technical reports have been excluded. \\
Articles with no available complete text have been rejected. \\
The non-English articles. \\
The articles with no relation to the research questions. \\
The identical articles. \\
\hline
\end{tabular}

\section{2-4. Search Terms}

We used the terms and "deep learning", "Internet of Things" or "loT" to search the articles in the mentioned databases. The same term was used in the mentioned databases. we only searched the title of articles assuming that novelty is generally stated in the title of databases.

\section{2-5. Review steps}

The articles have been selected according to the following steps:

- The search terms are used to search the five databases mentioned in Section 2-2.

- The non-selection criteria eliminate some of the articles.

- After reading the title and the abstract of articles, irrelevant ones are ignored.

- By completely reading the articles, the most significant ones are selected.

\section{Primary Research On Classification Plans}

In this article, to study and analyze articles in the two fields of loT and deep learning, we have categorized them based on the main idea of the articles. According to this view, the articles are classified into four main categories. Figure 2 reveals these categories. The articles in the 'Focus on data' category deal with loT data processing to get ready for being used in deep models. The articles in this category sometimes review data representation in a new way or extract the appropriate features or reduce data dimensions. In the 'Network' category, the reviewed articles are distributed into three groups; in the first one, the articles are focused on the utilized network or a change in the loT network. In this category, we put these articles in the branch of the 'Network Technology'. Deep learning needs many resources, including processor, battery power, and memory for the training itself; as a result, it cannot be appropriate for loT devices to have resource constraints. Thus, in some articles, they presented methods for scheduling tasks on the loT and adjusting the computational load to improve the consumption of resources. These articles are in the 'Resource Management' section. Guaranteeing privacy and security of information is one of the most important considerations in numerous loT applications and the reason is that the loT data are sent to analyze via the Internet and are thus visible around the world. Since many applications use anonymization, hacking and re-unification of these strategies as unnamed data will be possible. Further, biased attacks such as entering incorrect data or testing inputs by competitors threaten the Deep Learning (DL) training models; several efficient or inefficient conditions (such as availability, 
reliability, validity, certainty, etc.) may be at risk with these attacks. We classified articles that focus on the privacy and security of information into the 'Security' category.

As shown in Figure 2, the 'Computing Environment' category includes cloud, fog, and edge, along with their combined application, as well as big data analysis. Since the loT devices have computational constraints and cannot quickly handle the deep learning model computations, some articles have implemented their computations in a different context so that they can apply their proposed model. Articles that use deep learning with loT to present a new application have also been classified and reviewed in the 'Application' category.

By searching the mentioned databases, 151 articles were found on the Internet of Things and deep learning which met the criteria stated in Table 1. After selecting and removing articles, we reached 32 articles. These 32 selected articles included 7 conference articles and 25 journal articles, and from the latter, 19 articles had Q1 qualitative level, 3 articles had Q2 qualitative level, and 3 articles, despite their scientific value, had no recorded qualitative status on the site https://www.scimagojr.com/journalrank.php.

Table 2 reports the number of articles reviewed in five article databases, ACM, IEEE, Science Direct, Springer, and Wiley. In the Wiley database, there was no article in the loT and deep learning domain, therefore, Table 2 lists this database.

Table. 2. The number of selected articles based on publishers and the year of Publication

\begin{tabular}{|llllllll|}
\hline Publisher & ACM & IEEE & & \multicolumn{3}{c|}{ Science Direct } & Springer \\
\hline Year & 2018 & 2017 & 2018 & 2019 & 2018 & 2019 & 2017 \\
Number of Article & 1 & 2 & 15 & 5 & 5 & 3 & 1 \\
\hline
\end{tabular}

We categorized and analyzed the selected articles in four categories: 'Focus on Data Management, Network, Computing Environment, and Application'. Figure 3 illustrates the number of publications and their percentage in comparison to the articles reviewed. In the following sections, we will review the articles in each category.

\section{3-1. Primary Studies of 'Data Management'}

In this section, the primary studies on the loT and deep learning are investigated whereby it is determined that $25 \%$ of primary studies focused on Data Management.

Wang and Zhang [18] proposed a tensor DL model for heterogeneous data fusion in loT. In this article, the authors used the tensor space for simulating the strongly non-linear distribution of loT big data. They introduced tensor distance and high-order backpropagation for extending the data from linear to multilinear space. Finally, the proposed algorithm was compared to the stacked autoencoder and multimodal deep learning in STL-10 and CUAVE datasets. The authors detailed improved accuracy and data fusion compared to the two mentioned methods.

In 2018, Liang [19] proposed a fast and smart data processing scheme to achieve a quicker calculation in deep learning for realtime applications. In this study, the pre-processing of data was regarded as the main objective. Generally, data pre-processing is usually done in two categories: reduction of the data to subsets with their main features, and data transformation for eliminating some of the main features. In this study, in the preprocessing phase, the combination of both categories has been applied to take all their advantages and consequently preserve the physical properties of original data which is used as a linear in the selected subset. The offered method was evaluated through two large-scale dataset scenarios and big data. The authors proposed the SVD-QR in a large-scale data scenario for selecting sub-datasets. The SVD is applied to sort out individual values and their corresponding single vector while also determining the size of the dataset by single values. On the other hand, the QR is used for selecting the data sample as the deep learning input. In the big data scenario, Limited Memory Subspace Optimization is applied for SVD (LMSVD). This method uses large matrices to calculate outstanding single values based on the optimization of Krylov's subspace, and then they are selected by applying QR data. The proposed method was simulated through handwriting recognition which is used widely in most loT applications. After data preparation in the pre-processing 
phase, data are sent to the deep feedforward neural network based on the two mentioned scenarios. The outcomes demonstrate that the method is a powerful technique in deep learning and also, the SVD_QR method effectively reduces the input data and energy consumption.

Bu et al. [20] proposed a multi-projection deep computation model for the smart data in loT. They utilized the Multi-Projection Deep Computation Model (MPDCM) and generalized the DPDCM through replacing all hidden layers of the deep computation model with a multi-projection layer. Firstly, the MPDCM mapped each multi-modal object to various sub-spaces for demonstrating hidden characteristics in various subspaces. Then, the Multi-Projection autoencoder (MPTSE) learned interactive intrinsic properties from obtaining correlation by mapping the sub-space to the output. They designed a similar option of the MPDCM for training the parameters of the MPDCM based back-propagation and gradient descent. Then, they examined their idea for classification accuracy in Animal-20 and NUS-WIDE-14 datasets and compared them with DPDCM. The results indicated that MPDCM, with increasing numbers of sub-spaces, can accomplish higher categorization accuracy than the DPDCM. This reflects the ability for learning big data features. Although the algorithm uses more subspaces than the DPDCM algorithm does, the computational and the time complexity are almost the same.

Li et al. [21] suggested that a Deep Convolutional Computation Model (DCCM) according to CNN can be applied to heterogeneous industrial big data. The DCCM extends the CNN from the vector space to the tensor space. This tensor-based model can show the hidden relationship over various modalities of the big data and represents heterogeneous things. The tensor can represent the structure of heterogeneous data while maintaining the data raw structures. These attributes allow us to investigate complementarity and mutuality across various modalities. In addition, the tensor may prevent several issues in the vector space, including singularity and dimension disaster. Therefore, they can be employed in various utilizations like feature extraction, pattern recognition, and data fusion. The other advantage of using the tensor space which is mentioned in this article is that it reduces the number of the free variables to avoid over-fitting and also shortens the training time. They introduced a high-order back-propagation algorithm for training the parameters of DCCM in the high-order space. The experimentations outlined in this article on the three data sets of CUAVE, SNAE2, and STL-10 indicated that duration of training of the deep convolutional computation model was longer than that of CNN due to using more weights while it is less timeconsuming than the DCM method because by taking a pooling strategy and local receptive strategy in the tensor space, the number of the weights can be reduced efficiently.

Mohammadi et al. [8] utilized semi-supervised learning methods for solving the problem of the lack of labeled data on loT. They provided a deep reinforcement learning (DRL) algorithm according to the Bluetooth Low Energy (BLE) indoor intelligent location in a smart city. The experimental findings of this new algorithm suggested the efficiency of the semi-supervised DLM compared to the supervised deep learning model. This model uses the Variational Autoencoder (VAE) as the inference engine to generalize optimal policies. Moreover, the proposed model explores the extension of reinforcement deep learning to the semisupervised and provides a general framework for all types of loT programs.

Yao et al. proposed four fundamental questions concerning the interaction between human beings and physical objects with the potential of deep learning. They examined the answers to questions as follows: which deep neural network structure can effectively be used to process and combine sensor data in different utilizations?, How to decline the resource use of DLMs in order to fully use them on the resource-constrained loT instruments?, How can confidence measures be calculated in DL predictions?; and How can one reduce the need for labeled data?" [22].

The DeepSense framework has been introduced as an effective structure for processing and combining sensor data across different applications with minor changes. This framework contains a recurrent neural network (RNN) and convolutional neural network (CNN) and divides the sensor data into time intervals in order to process the time series data. DeepSense uses a convolutional network on sensors to encode local features and efficiently combine sensor data and RNN to extract time patterns. This framework can be used for both categorization and estimation issues. In this article, Deepsense has been used to identify heterogeneous human activity recognition (HHAR) as well as user identification with the biometric motion analysis (User ID). By comparing Deepsense with other deep learning designs, they showed that this framework is more effective than the methods outlined in this article. Yao et al. also introduced the DeeploT Compact Framework. The purpose of this framework 
is to discover the optimum dropout for the hidden element in the respective neural network. The evaluation of the DeeploT compression algorithm suggested that it can decrease the size of the network, energy consumption, and runtime while preserving accuracy. A comparison of this framework with other methods of deep learning has also been outlined in this research. Further, a brief introduction has been presented in this article on the Well-Calibrated algorithm, which is an uncertain estimation algorithm for MLP called RDeepSense. RDeepSense uses a new loss function called tunable that is the weighted sum of the negative log-likelihood as well as mean squared error. They showed that this method provides high-quality uncertainty estimation [22].

In another article, Yao et al.'s study introduced a semi-supervised framework on loT [23]. The proposed framework (SenseGAN) consists of three sections: a generator, a classifier, and a discriminator. The generator section generates data similar to sensed data. Then, the classifier section labels these data such that the discriminator could not make a distinction between the actual and the simulated data. This process is repeated until the classifier is trained well. The proposed framework used a convolutional structure and Deepsense for the classifier. The authors evaluated this framework on three datasets as user identification with biometric motion analysis (User ID), Wi-Fi signal-based gesture recognition (Wisture), and HHAR. The evaluations outlined in the article revealed that this framework is suitable for labeled and unlabeled data and can promote the classifier predictability without any timely operation and energy consumption.

Moreover, Khelifi et al.'s [24] study proposed numerous methods according to DLMs for loT utilization. They introduced Edge of Information-Centric loT to decrease latency time-critical applications. The authors proposed a confusion method to join ICN, IoT, and Edge computation. They applied RNN to process online data to save the history of the exchanged data and future predictions. A key advantage of this new technique has been considered to be a reduction in the volume of data and computation and processing assignments of diverse data in a real-time scheme.

The primary studies conducted on DLMs \& loT which focused on the data are surveyed and analyzed. Our considerations are outlined in Tables 3 and 4. Table 3 reports Ref \& year, Main idea of the study, advantages, and disadvantages.

Table. 3. A review of articles focused on 'Data Management' 


\begin{tabular}{|c|c|c|c|}
\hline $\begin{array}{l}\text { Ref } \\
\& \\
\text { year }\end{array}$ & Main Idea & Advantages & Disadvantages \\
\hline $\begin{array}{l}{[18],} \\
2018\end{array}$ & Applying tensor spaces & $\begin{array}{l}\text { - Simulating the nonlinear } \\
\text { distribution of big data using } \\
\text { Tensor } \\
\text { - Improving heterogeneous data } \\
\text { composition } \\
\text { - Better accuracy in detection } \\
\text { than CDL and MML for big data }\end{array}$ & $\begin{array}{l}\text { In the data integration, all data is } \\
\text { considered and additional data is not } \\
\text { deleted }\end{array}$ \\
\hline $\begin{array}{l}{[19],} \\
2018\end{array}$ & $\begin{array}{l}\text { Preprocessing data by using } \\
\text { SVD-QR and LMSVD-QR }\end{array}$ & $\begin{array}{l}\text { - Increasing computational } \\
\text { speed } \\
\text { - Reducing energy consumption }\end{array}$ & $\begin{array}{l}\text { To increase the speed of computation just } \\
\text { focusing on pre-processing }\end{array}$ \\
\hline $\begin{array}{l}{[20],} \\
2019\end{array}$ & $\begin{array}{l}\text { Applying Multi projection deep } \\
\text { computation model }\end{array}$ & $\begin{array}{l}\text { - High accuracy } \\
\text { - Time complexity and } \\
\text { computational is the same as } \\
\text { DPDCM }\end{array}$ & $\begin{array}{l}\text { The classification results are unstable due } \\
\text { to the effect of primary parameters }\end{array}$ \\
\hline $\begin{array}{l}{[21],} \\
2018\end{array}$ & Applying tensor space & $\begin{array}{l}\text {-Avoiding singularity and } \\
\text { dimension disaster. } \\
\text { - Achieving more acceptable } \\
\text { categorization than the DCM } \\
\text { and MDL without a high training } \\
\text { cost. } \\
\text { - Reducing the number of } \\
\text { weights in the tensor space. }\end{array}$ & $\begin{array}{l}\text { The suggested model contains rather } \\
\text { parameters in the high-order tensor space. }\end{array}$ \\
\hline $\begin{array}{l}{[8]} \\
2018\end{array}$ & $\begin{array}{l}\text { Applying semi-supervised deep } \\
\text { reinforcement learning for } \\
\text { dissolving the issue of the lack of } \\
\text { labeled data }\end{array}$ & $\begin{array}{l}\text { - The model learned the optimal } \\
\text { action policies resulting in a } \\
\text { better estimation of the target } \\
\text { locations. }\end{array}$ & Disadvantages are not mentioned \\
\hline $\begin{array}{l}{[22],} \\
2018\end{array}$ & $\begin{array}{l}\text { Introducing a new framework for } \\
\text { the purposes mentioned in the } \\
\text { article }\end{array}$ & $\begin{array}{l}\text {-Reducing the running time } \\
\text {-Reducing the need for labeled } \\
\text { data } \\
\text {-Increasing the accuracy }\end{array}$ & $\begin{array}{l}\text { Further investigations are necessary to } \\
\text { better confirm the applicability of the } \\
\text { results. }\end{array}$ \\
\hline $\begin{array}{l}{[23],} \\
2018\end{array}$ & $\begin{array}{l}\text { Introducing SenseGAN } \\
\text { framework }\end{array}$ & $\begin{array}{l}\text {-Training model with } 10 \% \text { of } \\
\text { labeled data }\end{array}$ & $\begin{array}{l}\text { It does not optimize for Multi-sensor data. } \\
\text { It only takes into account the category and } \\
\text { does not pay attention to the regression. } \\
\text { The learning process has a tricky } \\
\text { computation }\end{array}$ \\
\hline $\begin{array}{l}{[24],} \\
2019\end{array}$ & $\begin{array}{l}\text { Combining Edge computing and } \\
\text { ICN and loT }\end{array}$ & $\begin{array}{l}\text {-Reducing latency time-critical } \\
\text { application } \\
\text {-Reducing the volume of data } \\
\text {-Computing and processing in } \\
\text { real-time } \\
\text { - Improving the reliability and } \\
\text { function/performance. } \\
\text { - Mitigating the deployment } \\
\text { complexity, and enhancing the } \\
\text { flexibility of the network } \\
\text { communication. }\end{array}$ & The training time is high \\
\hline
\end{tabular}

Table 4 compares the articles in the 'Focus on Data' domain. In this table, we compare articles based on the year of their publication, experimental type, applied learning model, models compared, dataset, comparative criteria, tools, and language. The experimental type specifies the proposed scheme's type. This feature determines the designer type as numerical analysis, implementation, simulation, design, and mathematical proof. The Applied deep learning model feature characterizes the model used in the idea expressed in the article. The Compare Model feature shows the models that were compared with the articles while the Dataset determines the database used by the authors. The Comparison Criterion shows the criteria used by authors to compare the models while the Tool and Language describe the tools and programming language used, respectively.

Table. 4. A review of articles focused on 'Data Management' 


\begin{tabular}{|c|c|c|c|c|c|c|}
\hline $\begin{array}{l}\text { Ref } \\
\& \\
\text { year }\end{array}$ & $\begin{array}{l}\text { Experimental } \\
\text { Type }\end{array}$ & $\begin{array}{l}\text { Applied Deep } \\
\text { learning } \\
\text { Model }\end{array}$ & $\begin{array}{l}\text { Compare } \\
\text { Models }\end{array}$ & Dataset & $\begin{array}{l}\text { Comparative } \\
\text { Criterion }\end{array}$ & $\begin{array}{l}\text { Tool } \\
\& \\
\text { Language }\end{array}$ \\
\hline $\begin{array}{l}{[18]} \\
2018\end{array}$ & Simulation & TDL & $\begin{array}{l}\text {-SAE[1] } \\
-\mathrm{MDL}[2]\end{array}$ & $\begin{array}{l}\text { - CUAVE } \\
\text { - STL-10 }\end{array}$ & $\begin{array}{l}\text { - } \\
\text { Performance } \\
\text { - Detection } \\
\text { rate }\end{array}$ & $\begin{array}{l}\text { - Matlab } \\
- \\
\text { Tensorflow }\end{array}$ \\
\hline $\begin{array}{l}{[19]} \\
2018\end{array}$ & Simulation & $\begin{array}{l}\text { Feed forward } \\
\text { (NN) }\end{array}$ & - & Ex3data1.mat & $\begin{array}{l}\text { - Running } \\
\text { time } \\
\text { - Accuracy }\end{array}$ & - Matlab \\
\hline $\begin{array}{l}{[20]} \\
2019\end{array}$ & Implementation & Auto-encoder & DPDCM & $\begin{array}{l}\text { - Animal-20 } \\
\text { - NUS-WIDE-14 }\end{array}$ & - Accuracy & $\begin{array}{l}\text { Not } \\
\text { mentioned } \\
\text { in the } \\
\text { article }\end{array}$ \\
\hline $\begin{array}{l}{[21]} \\
2018\end{array}$ & Simulation & $\mathrm{DCCM}^{[3]}$ & $\begin{array}{l}\mathrm{DCM}^{[4]} \\
\mathrm{MDL}\end{array}$ & $\begin{array}{l}\text { - CUAVE } \\
\text { - SNAE2 } \\
\text { - STL-10 }\end{array}$ & Accuracy & $\begin{array}{l}\text { Not } \\
\text { mentioned } \\
\text { in the } \\
\text { article }\end{array}$ \\
\hline $\begin{array}{l}{[8],} \\
2018\end{array}$ & Implementation & DRL & $\begin{array}{l}\text { Supervised } \\
\text { method }\end{array}$ & $\begin{array}{l}\text { Prepared from a real-world } \\
\text { extension of a net of } \\
\text { iBeacons }\end{array}$ & $\begin{array}{l}\text {-Accuracy } \\
\text {-Average } \\
\text { reward } \\
\text {-Average } \\
\text { distance }\end{array}$ & $\begin{array}{l}\text { - } \\
\text { Tensorflow } \\
\text { - Keras }\end{array}$ \\
\hline $\begin{array}{l}{[22]} \\
2018\end{array}$ & Simulation & $\begin{array}{l}\text { CNN } \\
\text { RNN }\end{array}$ & $\begin{array}{l}\text { DS-single } \\
\text { GRU } \\
\text { DS- } \\
\text { nolndvConv } \\
\text { Ds- } \\
\text { noMergeconv } \\
\text { SparseSep }\end{array}$ & $\begin{array}{l}\operatorname{HHAR}^{[5]} \\
\text { UserID }^{[6]}\end{array}$ & $\begin{array}{l}\text { - Running } \\
\text { time } \\
\text { - Accuracy }\end{array}$ & $\begin{array}{l}\text { Not } \\
\text { mentioned } \\
\text { in the } \\
\text { article }\end{array}$ \\
\hline $\begin{array}{l}{[23],} \\
2018\end{array}$ & Simulation & GAN & $\begin{array}{l}\text { SenseGAN, } \\
\text { Semi-RF, } \\
\text { S3VM, } \\
\text { DeepSense, } \\
\text { RF, SVM }\end{array}$ & $\begin{array}{l}\text { HHAR } \\
\text { UserID } \\
\text { Wisture }^{[7]}\end{array}$ & $\begin{array}{l}\text { - Run time } \\
\text {-Energy } \\
\text { consumption } \\
\text {-Accuracy } \\
\text {-F1 score }\end{array}$ & $\begin{array}{l}\text { Not } \\
\text { mentioned } \\
\text { in the } \\
\text { article }\end{array}$ \\
\hline $\begin{array}{l}{[24]} \\
2019\end{array}$ & Design & $\begin{array}{l}\text { CNN } \\
\text { RNN } \\
\text { RL }\end{array}$ & - & - & - & $\begin{array}{l}\text { Not } \\
\text { mentioned } \\
\text { in the } \\
\text { article }\end{array}$ \\
\hline
\end{tabular}

\section{3-3. Primary Studies of Network}

In this section, the primary studies on the loT and deep learning are investigated whereby it is determined that $31 \%$ of primary studies have focused on the Network.

The framework based on Software-Defined Networks (SDN) was presented in [25]. The proposed architecture was scalable and flexible as well as secure for loT. The architecture included a layer for loT and an SDN layer. The SDN layer consisted of controlling and back warding layers, which were based on an intrusion detection system which is a hardware and software system designed for monitoring traffic attacks. Therefore, the authors used Restricted Boltzmann Machines (RBM) for intrusion detection. This network included two steps including forward and backward. According to the forward step, the hidden nodes are a function of the input, weights, biases, and active or passive activity function with the decision at the beginning being stochastic. On the other hand, this step output is a probability vector. In the backward step, samples of the output will be selected of which input will be mad. They used the KDD99 dataset for detecting four types of attacks and intrusion. They claimed that the accuracy of intrusion detection was far higher than that of other methods, and improved by about $9 \%$. 
In another article [26], for managing the industrial IoT, SDN was used dynamically and the Software-Defined Industrial Internet of Things (SDIloT) was introduced. In SDIloT, a large amount of data and flow were created through the industrial instruments, wherein there is a distributed, but reasonably focused, physical controller. However, one of the most difficult issues is how to achieve an agreement between multiple controls in complex industrial environments. In this article, an agreement protocol on Block Cycle (BC) is proposed. For Distributed SDIloT, a BC is capable of acting as a trusted and out-of-band the third party for coordinating between different SDN controls in a secure, reliable, and traceable way. The authors of this article utilized permissioned $\mathrm{BC}$ because of its low costs, less delay, and being low band-intensive. They considered the change in sight, the choice of access, and the allocation of computing resources as a joint optimization problem. Also, with Marco's decision making, they proposed a new method of dueling deep Q-learning. The results of the simulation showed the convergence and the efficiency of this new technique. Finally, the authors also argued that the procedure of measuring the trustworthiness of nodes can be considered as a matter of great importance for future studies.

McDermott et. al [27] provided a solution to identify botnet activities on consumer and network loT devices. Their proposed method involved the development of the Bi-directional Long Short-Term Memory based Recurrent Neural Network (BLSTMRNN). To identify the text and convert attack packets to the correct tokenized format, embed words were used. By examining the accuracy and error, a comparison was made between this new method and the LSTM-RNN and then identified the 4 attack vectors by Mirai botnet. The authors created a dataset containing four attack vectors for the Mirai botnet. Then, the researchers tested and evaluated it for 4 attack vectors including UDP, Mirai, ack, and DNS. The new method worked properly for UDP, DNS, and Mira attack vectors, and had respectively $98 \%, 98 \%$, and $99 \%$, coefficients of reliability. However, it did not work completely for the ack attack vector as it requires more training data.

In another article [28], a wireless device identification platform using deep learning techniques was introduced to provide security. Radiofrequency Fingerprint (RF) as one of the physical layer authentication methods can be employed for detecting licensed (allowed) wireless devices. In fact, DL is an acceptable way to achieve the features of various RF instruments by learning their RF data. This article focused on the ZigBee device (IEEE802.15.4) in wireless sensor networks, where ZigBee can use multiple network topologies such as stars, trees, and mesh to transfer data from the source to the base station or other peer-to-peer nodes. RF signals (IQ) are collected by the USRP device from multiple ZigBee devices, for training. These signals are then collected from devices that are already registered on the network and are listed. Next, using this labeled data, the proposed DL-based model is constructed. Upon the training, it is possible to apply the model to detect devices on the network. This new model has been considered to be transparent and passive to the RF devices and hence it is not necessary to install additional software/hardware on the wireless tools. In this article, six different types of ZigBee devices were considered. All the six ZigBee devices were configured for transferring from five distinctive SNR levels. The data collected from these six devices were 300 gigabytes and suitable for training a deep learning model. They investigated three models of deep learning improvement, namely DNN, CNN, and LSTM. The benefit of DL is the ability for automatic extraction of the features. The classification results could be utilized for intrusion detection, and a warning can be issued for an unregistered attacker's security breach.

In an article [29], the authors introduced an Internet-based system for deep learning for detecting anomalies in the Internet Industry Control System (IICS). The proposed method consisted of two sections; supervised and unsupervised. The unsupervised section aims at providing the initial values of the supervised section. AL-Hawawreh et al. used Deep Auto-Encoder (DAE) to provide the initial weights of the model parameters in the unsupervised section. Auto-Encoder uses input data to create the same data in the output and attempts for minimizing the errors generated by the data. Then, the trained model's parameters will constitute the starting point, the initial values of weights as well as biases for the Deep Feed Forward Neural Network (DFFNN). They used the two data sets UNSW-NB15 and NSL-KDD for evaluating this new model and compared them with the other methods. They found that their method outperformed other methods because of its dimension reduction and its automatic extraction of features. Further, it was easy to detect normal behaviors and attacks, as the model was initially trained by a normalized dataset. The extra training process performed on the model also protected the system against complex attacks. 
Ayadi and et Al. [30] used deep learning for routers in Named Data Networking (NDN) whereby the router could intelligently forward the packet. In the forwarding strategy, the responsible component for selection is the other hop according to the cost of the route, metrics of forwarding, and local policies. The application of the neural network is a way to predict the drop rate in the network according to the traffic prediction. The authors considered overload probability prediction in all links as one of the signals for minimizing the drop rate according to the new network status thereby increasing the output of the forwarded one. They used a linear function on the output layer and a two-layer feed-forward network with a sigmoid function on the hidden layer to design the DNN model. Then, the researchers applied the backpropagation algorithm for training the DNN model. A data set of static information for each router was made up of traffics in each link. They used a dataset available in the Dongo et al.'s project to evaluate their model and achieved $99.23 \%$ accuracy with four hidden neurons and over 70 epochs without the occurrence of over-fitting. Also, Ayadi et Al. assuming the support of loT devices from the NDN, reviewed the proposed method for the NDN-based audio conference.

In [31], the authors studied a large volume of information collected in loT and balanced the load on the network. They introduced an agent called Load Bot for effective load balancing in the domain of loT. This agent measures the load factor of the network and analyzes the configuration of the structure for enormous volume of data and enormous volume of the network load. Further, by applying the learning methods of deep beliefs, it can obtain effective load balances. They also introduced another factor called Balance bot based on the deep Q-learning algorithms to predict neural load. They created a grid-structured map using the deep-belief network by the RBM. Enhancing learning in deep learning is done through action while experiencing load learning in a given environment. The scalar reinforcement value is taken from evaluating the selected action. The Qlearning method does not compute the desired action from the current state; instead, it learns the number of tests and errors through optimal operation on any experiential conditions. Kim et al. used the Neural Prio Ensemble method described in the article [18] to predict the network load. When new data are entered, they are accumulated in a certain amount, and are transformed into a new, deep belief network, and are saved further. At this moment, the new belief network receives previous information on the network via Combining Load bot and Neural Prior Ensemble, learning all the network load, and extracting the weight-change process. By simulating their proposed scheme, they found that as the number of sensors on the Internet increased, the number of migrations did not increase, and compared to the dynamic methods, the proposed method was closer to optimal mode.

This study investigated a DL framework in order to perform dynamic watermarking on loT. It enabled the loT cloud framework to identify cyber-attacks and authenticate reliability. The proposed algorithm used the LSTM for extracting random properties such as spectral flatness, skewness, and kurtosis, as well as the central moments of the loT signals, with these properties being watermarked and placed alongside the original signal. The extracted features of the cloud prevented the attacker to read the watermarked data, and the eavesdropping attack would not be successful. This new LSTM reduced the complexity as well as a delay of the attack identification in comparison to the other security models. According to the simulation of the proposed algorithm, the attack was detected in less than 1 second and the loT signals could be sent with high reliability from the loT device to the cloud [32].

Ferdowsi et al. [33] in another article, in addition to the mentioned method, used the theory of games to accelerate the gateway decision-making to identify vulnerable loT devices. They stated that in massive loT scenarios, the verification of all devices at the same time is not possible due to computational (resources) constraints. The game theory-based framework can improve the identification of vulnerable devices. They provided two learning algorithms: The fictitious game algorithm which integrates the entire information of the entire state of the loT devices and converges to the mixed-strategy Nash equilibrium. The other is the deep reinforcement algorithm according to the LSTM blocks that can learn safe mode from previous gateway modes. Then, If the gateway information about the state of the loT devices is incomplete, it can predict it. The simulation results improve system protection by reducing about $30 \%$ of compromised loT devices.

Zhu and his colleagues [34] suggested a novel Deep Q Learning-based transmission scheduling method in the cognitive loT. This mechanism uses the Markov decision for describing various transmission states. They proposed a relay that equipped itself with a Q-learning algorithm for transmitting packets from another node to sink for improving performance. To boost the velocity of mapping between the state and activity, they used stacked autoencoders. In this article, the model was comprised of 
three algorithms including Strategy Iteration (SI), W learning (WL), and Random Selection (RS). They demonstrated that their model is more applicable than the Random Selection and the W Learning when they consider throughput, packet loss, and system utility. The model also outperformed WL when they considered power consumption. Although the proposed algorithm had a lower performance compared to the SI algorithm, its complexity was lower and could be applied to practical scenarios. The authors of this article argued that for the improvement of the proposed algorithm, it is possible to use multiple relays or coworker relays.

The primary studies in the field of deep learning and loT which focused on the network, are surveyed and analyzed. Our considerations are outlined in Tables 5 and 6. Table 5 lists the Ref \& year, Main Idea, Advantages, and Disadvantages.

Table. 5. A review of articles focused on 'Network' 


\begin{tabular}{|c|c|c|c|}
\hline $\begin{array}{l}\text { Ref } \\
\& \\
\text { year }\end{array}$ & Main Idea & Advantages & Disadvantages \\
\hline $\begin{array}{l}{[25],} \\
2018\end{array}$ & $\begin{array}{l}\text { Proposing a framework based } \\
\text { on SDN for intrusion detection }\end{array}$ & $\begin{array}{l}\text { - scalable } \\
\text { - High detection } \\
\text { rate }\end{array}$ & $\begin{array}{l}\text { - Requiring practical implementation of the proposed } \\
\text { architecture }\end{array}$ \\
\hline $\begin{array}{l}{[26]} \\
2019\end{array}$ & $\begin{array}{l}\text { Dueling Deep Q-Learning and } \\
\text { blockchain }\end{array}$ & $\begin{array}{l}\text { - Increasing } \\
\text { throughput } \\
\text { - high performance } \\
\text {-No need for edge } \\
\text { computing }\end{array}$ & $\begin{array}{l}\text { - Not taking into account the confidence features of nodes } \\
\text { and controllers } \\
\text { - Not comparing with other methods }\end{array}$ \\
\hline $\begin{array}{l}{[27],} \\
2018\end{array}$ & $\begin{array}{l}\text { Developing a detection model } \\
\text { based on BLSTM-RNN }\end{array}$ & $\begin{array}{l}\text { - High accuracy } \\
\text { - Low loss }\end{array}$ & $\begin{array}{l}\text { - It does not work well for the ack attack vector because it } \\
\text { requires more training data }\end{array}$ \\
\hline $\begin{array}{l}{[28],} \\
2018\end{array}$ & $\begin{array}{l}\text { The deep learning model for } \\
\text { identifying devices on a } \\
\text { wireless network }\end{array}$ & $\begin{array}{l}\text { - High accuracy } \\
\text { - extracting } \\
\text { features } \\
\text { automatically } \\
\text { - Passive and } \\
\text { transparent to RF } \\
\text { devices }\end{array}$ & Not comparing with other methods \\
\hline $\begin{array}{l}{[29],} \\
2018\end{array}$ & $\begin{array}{l}\text { Providing a two-stage deep } \\
\text { learning method for anomaly } \\
\text { detection }\end{array}$ & $\begin{array}{l}\text { - Decreasing } \\
\text { dimension } \\
\text { - Extracting auto } \\
\text { feature } \\
\text { - Resistant to } \\
\text { complex attacks } \\
\text {-High accuracy for } \\
\text { attack detection }\end{array}$ & $\begin{array}{l}\text { Selecting its parameters for the preprocessing phase is } \\
\text { important, this can be not considered the main subject } \\
\text { was given the current availability of complex and rapid } \\
\text { equipment. }\end{array}$ \\
\hline $\begin{array}{l}{[30],} \\
2018\end{array}$ & $\begin{array}{l}\text { Deep Learning for Packet } \\
\text { Forwarding }\end{array}$ & $\begin{array}{l}\text { - Reducing the } \\
\text { complexity of } \\
\text { network prediction } \\
\text { dynamically } \\
\text { - Depending on } \\
\text { routing protocols } \\
\text { - Avoiding } \\
\text { congestion }\end{array}$ & $\begin{array}{l}\text { - Other deep learning models can be used instead } \\
\text { - No comparison with other methods } \\
\text { - Random initialization of the model }\end{array}$ \\
\hline $\begin{array}{l}{[31]} \\
2017\end{array}$ & $\begin{array}{l}\text { Proposing LoadBot and } \\
\text { Balancebot for load balancing }\end{array}$ & $\begin{array}{l}\text { - Not increasing } \\
\text { migration when } \\
\text { increasing number } \\
\text { of sensors } \\
\text { - closing to the } \\
\text { optimal mode }\end{array}$ & - comparing with more models should be done \\
\hline $\begin{array}{l}{[32],} \\
2018\end{array}$ & $\begin{array}{l}\text { Deep Learning-Based Dynamic } \\
\text { Watermarking }\end{array}$ & $\begin{array}{l}\text { - Identify the } \\
\text { attack less than } 1 \\
\text { S } \\
\text { - High reliability } \\
\text { - High accuracy } \\
\text { - Low complexity }\end{array}$ & not simultaneously authenticate all devices \\
\hline $\begin{array}{l}{[33],} \\
2019\end{array}$ & $\begin{array}{l}\text { The theory of games and } \\
\text { deep reinforcement learning to } \\
\text { accelerate the gateway } \\
\text { decision making }\end{array}$ & $\begin{array}{l}\text { - Suitable for the } \\
\text { massive loT } \\
\text { - Identify the } \\
\text { attack less than } 1 \\
\text { s } \\
\text { - High reliability } \\
\text { - High accuracy } \\
\text { - Low complexity }\end{array}$ & \\
\hline $\begin{array}{l}{[34],} \\
2018\end{array}$ & $\begin{array}{l}\text { Using deep learning and Q- } \\
\text { learning for Transmission } \\
\text { Scheduling Mechanism }\end{array}$ & $\begin{array}{l}\text { - Low complexity } \\
\text { - Applicable for } \\
\text { practical } \\
\text { applications }\end{array}$ & - Lower performance than SI algorithms \\
\hline
\end{tabular}


Table 6 exactly functions like Table 4 regarding the comparison of articles based on the publication, experimental type, and other features.

Table. 6. A review of articles focusing on 'Network'

\begin{tabular}{|c|c|c|c|c|c|c|}
\hline $\begin{array}{l}\text { Ref } \\
\& \\
\text { year }\end{array}$ & $\begin{array}{l}\text { Experimental } \\
\text { Type }\end{array}$ & $\begin{array}{l}\text { Applied } \\
\text { Deep } \\
\text { learning } \\
\text { Model }\end{array}$ & Compare Models & Dataset & $\begin{array}{l}\text { Comparative } \\
\text { Criterion }\end{array}$ & $\begin{array}{l}\text { Tool } \\
\& \\
\text { Language }\end{array}$ \\
\hline $\begin{array}{l}{[25]} \\
2018\end{array}$ & Simulation & RBM & SVM, PCA & KDD99 & Precision & $\begin{array}{l}\text { Tensorflow } \\
\text { Python }\end{array}$ \\
\hline $\begin{array}{l}{[26]} \\
2019\end{array}$ & $\begin{array}{l}\text { - Simulation } \\
\text {-Theoretical } \\
\text { analysis }\end{array}$ & $\begin{array}{l}\text { Dueling } \\
\text { Deep Q- } \\
\text { Learning }\end{array}$ & - & $\begin{array}{l}\text { Simulate in a real } \\
\text { environment }\end{array}$ & Throughput & $\begin{array}{l}\text { Tensorflow } \\
\text { Python }\end{array}$ \\
\hline $\begin{array}{l}{[27],} \\
2018\end{array}$ & Simulation & $\begin{array}{l}\text { BLSTM- } \\
\text { RNN }\end{array}$ & LSTM-RNN & $\begin{array}{l}\text { Dataset made by } \\
\text { the authors }\end{array}$ & $\begin{array}{l}\text { Accuracy } \\
\text { loss }\end{array}$ & $\begin{array}{l}\text { TensorFlow } \\
\text { Keras } \\
\text { Theano }\end{array}$ \\
\hline $\begin{array}{l}{[28]} \\
2018\end{array}$ & Implementation & $\begin{array}{l}\text { CNN, DNN, } \\
\text { LSTM }\end{array}$ & - & $\begin{array}{l}\text { The dataset } \\
\text { includes data from } \\
\text { ZigBee devices }\end{array}$ & $\begin{array}{l}\text { Complexity } \\
\text { Performance } \\
\text { Training } \\
\text { time } \\
\text { Test time }\end{array}$ & $\begin{array}{l}\text { Tensorflow } \\
\text { Keras }\end{array}$ \\
\hline $\begin{array}{l}{[29]} \\
2018\end{array}$ & Simulation & $\begin{array}{l}\text { DAE }^{[8]} \\
\text { DFFN'N }\end{array}$ & $\begin{array}{l}\text { F-SVM, CVT } \\
\text { DMM, TANN } \\
\text { DBN, RNN }{ }^{[9]} \\
\text { DNN }\end{array}$ & $\begin{array}{l}\text { NSL-KDD UNSW- } \\
\text { NB15 }\end{array}$ & $\begin{array}{l}\text { Accuracy } \\
\text { Detection } \\
\text { rate } \\
\text { FPR } \\
\text { ROC } \\
\text { CPU TIME }\end{array}$ & $\mathrm{R}$ \\
\hline $\begin{array}{l}{[30]} \\
2018\end{array}$ & Simulation & $\mathrm{FFNN}^{[10]}$ & - & $\begin{array}{l}\text { Dataset Dongo et } \\
\text { al. }\end{array}$ & $\begin{array}{l}\text { - Average } \\
\text { download } \\
\text { latency } \\
\text { - Throughput } \\
\text { - Cache hit } \\
\text { ratio } \\
\text { - Interest } \\
\text { overhead }\end{array}$ & $\begin{array}{l}\text { Python } \\
\text { Numpy } \\
\text { ndnSIM }\end{array}$ \\
\hline $\begin{array}{l}{[31],} \\
2017\end{array}$ & Simulation & RBM & - & Not used dataset & $\begin{array}{l}\text { The number } \\
\text { of migration }\end{array}$ & Matlab \\
\hline $\begin{array}{l}{[32]} \\
2018\end{array}$ & Simulation & LSTM & - & $\begin{array}{l}\text { A real dataset from } \\
\text { an accelerometer }\end{array}$ & $\begin{array}{l}\text { - Time to } \\
\text { detect an } \\
\text { attack } \\
\text { - Accuracy }\end{array}$ & $\begin{array}{l}\text { Not } \\
\text { mentioned } \\
\text { in the } \\
\text { article }\end{array}$ \\
\hline $\begin{array}{l}{[33]} \\
2019\end{array}$ & $\begin{array}{l}\text { - Simulation } \\
\text { - Mathematical } \\
\text { proof }\end{array}$ & LSTM & - & $\begin{array}{l}\text { A real dataset from } \\
\text { an accelerometer }\end{array}$ & $\begin{array}{l}\text { Attack } \\
\text { detection }\end{array}$ & $\begin{array}{l}\text { Not } \\
\text { mentioned } \\
\text { in the } \\
\text { article }\end{array}$ \\
\hline $\begin{array}{l}{[34]} \\
2018\end{array}$ & Simulation & $\begin{array}{l}\text { Stack Auto } \\
\text { Encoder }\end{array}$ & $\begin{array}{l}\text { Strategy Iteration (SI), } \\
\text { Wlearning (WL), Random } \\
\text { Selection (RS) }\end{array}$ & Not used dataset & $\begin{array}{l}\text { Throughput } \\
\text { Power } \\
\text { Packet loss } \\
\text { System } \\
\text { utility }\end{array}$ & $\begin{array}{l}\text { Not } \\
\text { mentioned } \\
\text { in the } \\
\text { article }\end{array}$ \\
\hline
\end{tabular}

\section{3-4. Primary Studies of Computing Environment}

In this section, the primary studies on the loT and deep learning are investigated; it is determined that $25 \%$ of the previous studies have addressed the Computing Environment. 
Xuan et al.'s [35] study compared and evaluated three representing methods of Parallel Acceleration, Quantization, and Model Pruning to enable deep learning in the loT. They determined the impact of the above methods on the Nvidia Tegra X2 platform with two integrated cores of ARM and GPU. Two kinds of methods are used to apply DLMs on the edge of the loT; the first was to equip loT devices with CPU or ARM to enhancing their processing power and the second method is to use the middle layer to preprocess and provide data in processing on the loT. The authors of this study used both methods. For hardware acceleration, they considered multi-core implementation and optimization instructions. On the other hand, for the second method, the lightweight DL model was proposed and the pruning of the model was evaluated. Finally, the quantization method which concerns optimization at hardware levels and DL models were applied. The deep learning model used in this study was CNN, which was evaluated in different ways.

Wei et al. [36] pointed to cloud-based loT problems and provided a solution for the long delay and their back-haul bandwidth. They used fog-based loT to reduce service delays and maintain back-haul bandwidth. However, the loT performance is fogbased and is dependent on the effective and intelligent management of the network resources; thus collaboration of storage, communications, and computations is one of the major challenges to be solved. Their study simultaneously presented difficulties related to the content storage strategy, the computing discharge policy, and the radio resources allocation in order to provide a common optimization solution based on deep learning for fog-based loT. However, since the service requests and wireless signals exhibit random features, they utilize the actor-critical reinforced learning (RL) framework for solving the joint decision problem for minimizing latency. The DNN is employed in both the Actor and Critic sections. For the Critic section, it is used as the approximation function for estimating the value of functions with regard to the huge state and action space. On the other hand, the actor section is used to illustrate the parametric random policy and improve the policy to help the critic. The authors also used the gradient method to avoid convergence with maximum local value. The simulation results for offloading indicated that the tasks with low computational load were performed on the edge while those with heavy computational loads were performed in the cloud, whereby a better efficiency was achieved. Also, the average end-to-end service latency was reduced by increasing the number of nodes, while more bandwidth and sub-channels could be assigned to each user.

Tang et al. [37] developed the Convolutional Neural Network on the loT hardware. They applied the SqueezeNet architecture and the ARM Compute Library (ACL) for implementation, to boost the deep learning processing speed and to improve the latency time in the offloading computation. The authors used the Nanomsg messaging framework to exchange messages between tasks on the loT and used an NNVM-based compiler to optimize the model. The presented method was implemented in Tensorflow by activating the optimization of the ARM NEON vector computations. Further, the NEON-capable building blocks were utilized in the development of the SqueezeNet engine. By comparing Tensorflow and ACL, they found that despite the higher memory and power consumption in the ACL library, its runtime was better by about 150 milliseconds.

Nowadays, fog computing is popular in loT as bandwidth and computational resources in centralized clouds are limited and the cloud is not sufficient to process and analyze a lot of data. In this regard, Lyu et al.'s [38] study demonstrated a three-level Fog Embedded Privacy-Preserving Deep Learning Framework (FPPDL) for preventing challenges such as privacy matters, response delays, computation, and communication bottlenecks. They proposed that computation is done in fog nodes close to the end equipment which developed a two-level privacy-preserving mechanism. Experimental results on 3 benchmark data sets to classify the images demonstrated that the proposed framework offers good accuracy and provides fault tolerance which is also scalable.

Diro et al.'s [39] study presented a distributed DLM capable of parallelizing the training and sharing of the parameters to local nodes in the fog. They analyzed their model on the NSL-KDD dataset for intrusion detection in computer networks. They performed their analysis on two parts; i) two classes (normal and attack); ii) four classes (Normal, DoS, Probe, R2L.U2R). The researchers used test data to detect the Zero-day attack which occurs frequently due to different protocols in the loT. They pursued two goals for the proposed algorithm. The first goal was to make a comparison between the findings of the distributed attack detection and a centralized system by implementing a DLM on a single node and numerous coordinate nodes for detecting the distributed attack. Moreover, the second aim was the evaluation of the impact of the DL algorithm against shallow learning to detect attacks on the loT-based systems. Following the hyper-parameter optimization, the DL system employed respectively 123 input characteristics, 150 neurons for the first layer, 120 and 50 neurons for the second and third layers. Finally, 
in the last layer, the number of neurons was the same as the number of classes. This model utilized a batch with various sizes and 50 epochs and applied Dropout to avoid overfitting.

Li et al. [40] provided an elastic model compatible with various models of deep learning on the loT with edge computation as well as an online algorithm for improving the service capacity and off-loading strategies to function properly. Because of the different measurements of intermediate data and pre-processing overhead in various DLMs, this study raises the problem of scheduling to maximize the number of the DL tasks via restricting the network bandwidth as well as service capacity of the edge nodes. In the next step, offline and online algorithms were introduced for solving the problems. The scheduling algorithm in this study was used for reducing the traffic load of a network while transmitting data from the sensors to a cloud server. This article referred to the edge server's limitation concerning the cloud server and applied the reduction of data size deep learning in higher layers whereby placement of the layers on the edge server could recover the network traffic. Nevertheless, as stated above, the edge server has its capacity limitations. Li and his colleagues first trained the DL network on a cloud server, and then divided the network into two parts, including lower layers close to the input data and higher layers close to the output data. The first part was used on the edge server while the second part was sent to the cloud server. In this study, an algorithm was proposed attempting to achieve the highest tasks in the computational edge structure by applying the deep layers on the loT edge server, where the delay of the transmission required for each task could be guaranteed. The deep Network was used in this article and CNN's ten-task network was run with various CNN networks. Also, the number of the operations and the intermediate data created in all layers were recorded. Li et al. showed that the input data diminished by DL networks, and most of the intermediate data decreased by the lower layers, while computational overhead enhanced with further layers.

In another article, Zhang et al. [41] presented the Adaptive Deep Computational Model (ADCM). They used this model for learning the characteristics of big data in the industrial loT. The adaptive dropout rate is designed by the adaptive distribution function to prevent overfitting and to adjust the activation rate according to the position of the layer. They also used the crowdsourcing technique, which is a combination of human intelligence with machine power reducing the issue of the availability of the training samples, to accumulate labeled samples for training the model parameters. It was found that the crowdsourcing technique with cloud computations can enhance the deep computational model performance. In order to have labeled training samples for a deep computational model, some unlabeled examples were transmitted to the cloud platform, and next the labels were achieved by collecting responses provided by human workers on the cloud platform. In this regard, the Response Collecting Method is SLME[11] which is designed for multiple labeling. The authors simulated their proposed method on the CUAVE and SNAE2 datasets. They found that their model suitability for preventing overfitting and providing labeled examples for training the deep computational model. Therefore, for evaluating the new method stability, all models were trained for 5 times, and then the average classification accuracy was employed to validate the efficiency of the proposed model. The authors stated that the results of this model could be improved by processing them on the initialization of the model.

The authors [42] presented an edge-based framework to establish a trade-off between the cost of communication and data freshness. In this framework, loT's transitional data intelligently understood the environment through DRL and Markov Decision Process (MDP) methods. They then selected and learned storage policy based on history and current raw observational environment. The results suggested that the long-term cost of the user was reduced while the prolonged usefulness of fetching transient data items increased.

In addition, the primary studies in the field of deep learning \& loT that focused on the Computing Environment are surveyed and analyzed. Our considerations are outlined in Tables 7 and 8 . Table 7 reports of the Ref \& year, Main Idea, Advantages, and Disadvantages.

Table. 7. A review of articles focused on 'Computing Environment' 


\begin{tabular}{|c|c|c|c|}
\hline $\begin{array}{l}\text { Ref } \\
\& \\
\text { year }\end{array}$ & Main Idea & Advantages & Disadvantages \\
\hline $\begin{array}{l}{[35],} \\
2018\end{array}$ & Compare representative approaches & $\begin{array}{l}\text { The DL capability on } \\
\text { the loT edge. }\end{array}$ & $\begin{array}{l}\text { Applying hardware and software together can } \\
\text { have a good impact on performance, but the } \\
\text { hardware is a costing method. }\end{array}$ \\
\hline $\begin{array}{l}{[36]} \\
2019\end{array}$ & $\begin{array}{l}\text {-Using simultaneous storage of content } \\
\text {-The policy of calculating } \\
\text {-The discharge and allocation of radio } \\
\text { sources } \\
\text {-Using fog }\end{array}$ & $\begin{array}{l}\text { - Minimize the } \\
\text { average end-to-end } \\
\text { latency }\end{array}$ & \\
\hline $\begin{array}{l}{[37]} \\
2017\end{array}$ & $\begin{array}{l}\text {-Using CNN inference engines on loT } \\
\text { devices } \\
\text { - Construction of shaft motors } \\
\text {-Review Offloading }\end{array}$ & $\begin{array}{l}\text { - Dominate the } \\
\text { restrictions of delay in } \\
\text { offloading }\end{array}$ & $\begin{array}{l}\text { - Applying ML/DL-based models involve } \\
\text { computational power, not low power } \\
\text { consumption, and sizeable storage to keep } \\
\text { the model } \\
\text { - Rendering the migration to onboard } \\
\text { deployment extra challenging }\end{array}$ \\
\hline $\begin{array}{l}{[38],} \\
2019\end{array}$ & $\begin{array}{l}\text { A fog-deep learning framework with } \\
\text { protecting the privacy }\end{array}$ & $\begin{array}{l}\text { - The communication } \\
\text { and computation } \\
\text { costs are greatly } \\
\text { reduced } \\
\text { - The favorable } \\
\text { tradeoff between } \\
\text { privacy and } \\
\text { performance }\end{array}$ & $\begin{array}{l}\text { - Results need more study using other data } \\
\text { sets }\end{array}$ \\
\hline $\begin{array}{l}{[39],} \\
2018\end{array}$ & $\begin{array}{l}\text { Introduce a deep-distributed learning } \\
\text { model to identify the attack }\end{array}$ & $\begin{array}{l}\text { - Better performance } \\
\text { than the centralized } \\
\text { model }\end{array}$ & $\begin{array}{l}\text { More comparison can perform by machine } \\
\text { learning algorithms and other datasets }\end{array}$ \\
\hline $\begin{array}{l}{[40]} \\
2018\end{array}$ & $\begin{array}{l}\text { - Use edge computing along with deep } \\
\text { learning } \\
\text {-Reduce input data using deep learning }\end{array}$ & $\begin{array}{l}\text {-Better performance } \\
\text { when deep learning } \\
\text { used and had a lot of } \\
\text { data } \\
\text {-Automatic extracting } \\
\text { features } \\
\text { - The privacy- } \\
\text { preserving in } \\
\text { intermediate data } \\
\text { transferring }\end{array}$ & $\begin{array}{l}\text { At the beginning of the work, the proposed } \\
\text { algorithm is less efficient than the rest of the } \\
\text { algorithms and shows its performance after a } \\
\text { long time. }\end{array}$ \\
\hline $\begin{array}{l}{[41],} \\
2019\end{array}$ & $\begin{array}{l}\text { Adaptive dropout } \\
\text { Crowdsourcing method } \\
\text { improve SLME }\end{array}$ & $\begin{array}{l}\text { - Preventing } \\
\text { Overfitting } \\
\text { Solving the problem } \\
\text { of the lack of labeled } \\
\text { data }\end{array}$ & $\begin{array}{l}\text {-The model output is dependent on the } \\
\text { initialization }\end{array}$ \\
\hline $\begin{array}{l}{[42],} \\
2019\end{array}$ & $\begin{array}{l}\text { Using DRL model for solving the } \\
\text { problem of caching loT data at the edge } \\
\text { without knowledge of the future } \\
\text { popularity of loT data. }\end{array}$ & $\begin{array}{l}\text { The tradeoff between } \\
\text { loss of data } \\
\text { freshness and cost of } \\
\text { communication. }\end{array}$ & $\begin{array}{l}\text { Cooperative caching in loT systems with } \\
\text { multiple edges is not considered }\end{array}$ \\
\hline
\end{tabular}

Again, Table 8 offers the same information as Tables 4 and 6, but for the Computing Environment domain.

Table. 8. A review of articles focused on 'Computing Environment' 


\begin{tabular}{|c|c|c|c|c|c|c|}
\hline $\begin{array}{l}\text { Ref \& } \\
\text { year }\end{array}$ & $\begin{array}{l}\text { Experimental } \\
\text { Type }\end{array}$ & $\begin{array}{l}\text { Applied Deep } \\
\text { learning Model }\end{array}$ & $\begin{array}{l}\text { Compare } \\
\text { Models }\end{array}$ & Dataset & $\begin{array}{l}\text { Comparative } \\
\text { Criterion }\end{array}$ & $\begin{array}{l}\text { Tool } \\
\& \\
\text { Language }\end{array}$ \\
\hline $\begin{array}{l}{[35]} \\
2018\end{array}$ & Implementation & CNN & $\begin{array}{l}\text { light-weight } \\
\text { CNN } \\
\text { deep CNN }\end{array}$ & VGGFACE2 & $\begin{array}{l}\text { - Accuracy } \\
\text { - speed up }\end{array}$ & $\begin{array}{l}\text { ARM platform } \\
\text { Nvidia Tensor } \\
\text { RT }\end{array}$ \\
\hline $\begin{array}{l}{[36]} \\
2019\end{array}$ & Simulation & DNN & & $\begin{array}{l}\text { Dataset made by } \\
\text { the authors }\end{array}$ & service latency & $\begin{array}{l}\text { Not mentionec } \\
\text { in the article }\end{array}$ \\
\hline $\begin{array}{l}{[37]} \\
2017\end{array}$ & Implementation & CNN & - & Not used dataset & $\begin{array}{l}\text { Executive Time } \\
\text { Latency }\end{array}$ & $\begin{array}{l}\text { TensorFlow } \\
\text { ACL }\end{array}$ \\
\hline $\begin{array}{l}{[38]} \\
2019\end{array}$ & Implementation & MLP & $\begin{array}{l}\text { Centralized } \\
\text { Standalone } \\
\text { DSSGD }^{[12]}\end{array}$ & $\begin{array}{l}\text { MNIST } \\
\text { SVHN }\end{array}$ & $\begin{array}{l}\text { Accuracy } \\
\text { Fault tolerance } \\
\text { Computation } \\
\text { Communication } \\
\text { Bandwidth } \\
\text { Response delay }\end{array}$ & TensorFlow \\
\hline $\begin{array}{l}{[39]} \\
2018\end{array}$ & Implementation & $\begin{array}{l}\text { Multi-layer deep } \\
\text { network }\end{array}$ & - & NSL-KDD & $\begin{array}{l}\text { Accuracy } \\
\text { DR } \\
\text { Precision } \\
\text { Recall } \\
\text { F-measure }\end{array}$ & $\begin{array}{l}\text { Keras } \\
\text { Theano } \\
\text { Spark }\end{array}$ \\
\hline $\begin{array}{l}{[40]} \\
2018\end{array}$ & Simulation & CNN & - & $\begin{array}{l}\text { The open dataset } \\
\text { from Kaggle }\end{array}$ & $\begin{array}{l}\text { - Reduced data } \\
\text { and operations } \\
\text { - Number of } \\
\text { deployed tasks }\end{array}$ & $\begin{array}{l}\text { Caffe } \\
\text { python } \\
\text { Network x } \\
\text { library }\end{array}$ \\
\hline $\begin{array}{l}{[41]} \\
2019\end{array}$ & Simulation & $\begin{array}{l}\text { ADDCM } \\
\text { ADDCM_DDC }\end{array}$ & $\begin{array}{l}\text { DCM } \\
\text { DDCM }\end{array}$ & $\begin{array}{l}\text { CUAVE } \\
\text { SNAE2 }\end{array}$ & Accuracy & Matlab \\
\hline $\begin{array}{l}{[42]} \\
2019\end{array}$ & Simulation & DRL & $\begin{array}{l}\text {-LRU } \\
\text {-Least Fresh } \\
\text { First (LFF) }\end{array}$ & Not used dataset & $\begin{array}{l}\text { Cache hit ratio } \\
\text { Freshness } \\
\text { Cost }\end{array}$ & $\begin{array}{l}\text { TensorFlow } \\
\text { Python }\end{array}$ \\
\hline
\end{tabular}

\section{3-5. Primary Studies of Application}

In this section, the primary studies on the loT and deep learning are investigated whereby it is determined that $19 \%$ of primary studies focused on the Application. The articles in this section have used the usual models of deep learning for a particular or a new application. Further, the authors' idea is to apply and comparing different types of applications with common deep learning models.

Sundaravadivel et al. [43] implemented a deep learning system for monitoring health, called Smart-Log. The five-layer DLM was established on a perceptron neural network with compact hidden layers for regulating nutrition after meals. They introduced a new algorithm-based Bayesian network for determining the nutritional features of food, offering meals and recipes. This algorithm was presented with an accurate analysis of different Bayesian classifiers with proper performance. The built system had a smart sensor board connected to the mobile application software. This board included weight sensors for food. The weight of the food was sent via wireless to the cloud. The facts about nutrition were obtained by a smartphone camera through the smartphone program. The system then provided nutrient values. The user could access the calculations of nutrients' values and predictions using the smartphone program.

To monitor patients' nutrition, Vellappally et al. [44] installed chips in the patients' teeth, which was an electrochemical sensor for collecting information about the used foods, including fat, salt, fat, sugar, and so forth. Therefore, the collected data could be used to evaluate the consumed food quality. In the next step, information collected was processed with the use of the bacterial optimization and DL network, reviewing the information of the loT through the self-learning process. According to the analysis, the loT device in the teeth reduced the mastication problems. Moreover, the advantage of the prediction system of 
food quality based on loT was implemented by MATLAB where the data from 53 patients were collected and 15 of them were used to test the model.

In another study, deep learning was used in medical loT. The medical Internet of things is capable of collecting massive medical data from ultrasound images, radiography, and magnetic resonance imaging. In this article, Yao et al. learned the features by using the CNN model and the back-propagation learning algorithm from the input data, and categorized and analyzed the various types of gallbladder stones [45].

Sun and his colleagues [46] employed CNN, RNN, and Hash technology for providing a user interface for a natural image and natural language query. Their proposed architecture consisted of four modules including image training, user query, text processing, image retrieval, and data storage. In the proposed architecture, both semantic information and image cognition were important. They evaluated their proposed method for the 4S Online Store and observed that it could be an effective platform.

In the article [47], an intelligent agricultural system was dealt with through deep learning. In this article, in addition to predicting suitable products for subsequent crop cultivation, optimization of the irrigation system in the field was also considered. A wireless network was used to collect supervisory data about soil parameters uploading data in the cloud. After analyzing by LSTM, the results were sent to the user by SMS.

Wang et al. [48] used deep learning in the usage of indoor localization, health care sense, and activity recognition. They provided a DL framework for RF sensing. Their proposed deep learning models for this framework included Autoencoder, CNN, and LSTM. The proposed framework consisted of a data collection section, preprocessing section, an offline section for training the deep learning model, an online section for data testing, and finally the conclusion section. The results indicated that the proposed framework was more accurate in the three mentioned usages.

The primary studies in the field of deep learning and loT which focused on the Application, are surveyed and analyzed. Our considerations are outlined in Table 9. Table 9 outlines the Ref \& year, Name of the application, Applied Deep Learning Model, and Tool.

Table. 9. A review of articles focused on 'Application'

\begin{tabular}{|llll|}
\hline Ref \& year & Name of Application & Applied Deep learning Model & Tool \\
\hline [43], 2018 & $\begin{array}{l}\text { A DL-based Automated } \\
\text { Nutrition Monitoring System in the loT }\end{array}$ & $\begin{array}{l}\text { - - } \\
\text {-Perceptron Network }\end{array}$ & Weka \\
\hline [44], 2019 & Nutrition Monitoring System & $\begin{array}{l}\text { Adaptive Deep } \\
\text { Learning Neural Network }\end{array}$ & Matlab \\
\hline$[45], 2019$ & Predicting chemical composition of gallstones & CNN & Not mentioned in the article \\
\hline$[46], 2018$ & Image Cognition Platform & VGGNet & Caffe \\
\hline$[47], 2017$ & Smart Agriculture & LSTM & Not mentioned in the article \\
\hline$[48], 2018$ & $\begin{array}{l}\text { Indoor localization } \\
\text { Activity Recognition } \\
\text { Healthcare Sensing }\end{array}$ & $\begin{array}{l}\text { Autoencoder } \\
\text { CNN } \\
\text { LSTM }\end{array}$ & Keras \\
\hline
\end{tabular}

\section{Results}

Upon the investigations and study of the publications, the questions mentioned in the present research are answered.

Reply to RQ1: What are the most appropriate and common tools, simulators, and datasets in the Internet of Things and Deep Learning field? 
As shown in Figure 4, having searched the published databases, 151 articles have been found in the field of loT and DL. Investigation of the recent trend in the number of articles has shown a significant boost in research and development in this field. Hardware transformations and enhanced processing speed can be among the major reasons for growing research on $\mathrm{DL}$ in loT.

Reply to RQ2: What are the most appropriate and common tools, simulators, and datasets in the Internet of Things and Deep Learning field?

Several different tools and software for deep learning by 2019 are outlined below. The following list has been obtained by checking websites such as [49], [50], [51] with the subject of tools and software associated with deep learning.

Apache MXNet, Apache SINGA, BigDL, Caffe, Chainer, Deeplearning4j, Intel Math Kernel Library, Dlib, Intel Data Analytics Acceleration Library, Keras, MATLAB + Deep Learning Toolbox, Microsoft Cognitive Toolkit (CNTK), PyTorch, R+ Deep Learning Toolbox, Tensorflow, Theano, Torch, Weka.

Table 10 presents the programming environments used by the authors of the examined articles to simulate their ideas. Also included in this table are the advantages, disadvantages, platform, and interface of each programming environment.

TensorFlow has been mostly used among the articles that cited their programming environment, while the Weka, R, and Caffe have been used Less frequently.

Table. 10. Comparison of deep learning environment programing 


\begin{tabular}{|c|c|c|c|c|c|}
\hline $\begin{array}{l}\text { Environment } \\
\text { of } \\
\text { programing }\end{array}$ & Disadvantages & Advantages & Platform & Interface & $\begin{array}{l}\text { Using in } \\
\text { Ref }\end{array}$ \\
\hline TensorFlow & $\begin{array}{l}\text { - Slower than other } \\
\text { frameworks } \\
\text { - Few related models } \\
\text { - Much "fatter" than } \\
\text { Torch } \\
\text { - Slow due to the } \\
\text { computational graph } \\
\text { based on Python } \\
\text { - No commercial support } \\
\text { - New training groups are } \\
\text { loaded after dropping } \\
\text { out of Python } \\
\text { - Dynamic typing leads } \\
\text { to some errors in large } \\
\text { software projects }\end{array}$ & $\begin{array}{l}\text { - LSTM training is fast } \\
\text { - Networks can be visualized } \\
\text { - Compile times are more } \\
\text { rapid than Theano } \\
\text { - Tensor Board for } \\
\text { visualization } \\
\text { - Data and model parallelism }\end{array}$ & $\begin{array}{l}\text { Linux, } \\
\text { macos, } \\
\text { Windows, } \\
\text { Android }\end{array}$ & $\begin{array}{l}\text { C/C++, Python - } \\
\text { Keras, Go, Java, } \\
\text { JavaScript, Julia, } \\
\text { R, Swift }\end{array}$ & $\begin{array}{l}\text { [26], [27], } \\
{[48],[25],} \\
{[37],[18]} \\
\text {,[42] }\end{array}$ \\
\hline Keras & & $\begin{array}{l}\text { - Fast Prototyping } \\
\text { - Low Dataset } \\
\text { - Multiple back-end support } \\
\text { - Intuitive API inspired by } \\
\text { Torch } \\
\text { - Operates with TensorFlow, } \\
\text { Deeplearning4j backends } \\
\text { (CNTK backend to come), \& } \\
\text { Theano. } \\
\text { - Fast-growing framework } \\
\text { - Likely to become standard } \\
\text { Python API for NNs }\end{array}$ & $\begin{array}{l}\text { Linux, } \\
\text { macOS, } \\
\text { Windows }\end{array}$ & $\begin{array}{l}\text { Linux, macOS, } \\
\text { Windows }\end{array}$ & $\begin{array}{l}\text { [8], [27], } \\
\text { [39], [48], } \\
\text { [28] }\end{array}$ \\
\hline Theano & $\begin{array}{l}\text { - Many low-level APIs } \\
\text { - unhelpfulness of the } \\
\text { error messages - Longer } \\
\text { compile times for big } \\
\text { models } \\
\text { - Much "fatter" than } \\
\text { Torch } \\
\text { - Patchy support for } \\
\text { pertained models } \\
\text { - Buggy on AWS } \\
\text { - Single GPU }\end{array}$ & $\begin{array}{l}\text { - Supports different models } \\
\text { - Rapid on LSTM training on } \\
\text { GPU } \\
\text { - RNNs properly fit in the } \\
\text { computational graph } \\
\text { - High-level wrappers (Keras, } \\
\text { Lasagne) relieve the pain }\end{array}$ & $\begin{array}{l}\text { Cross- } \\
\text { platform }\end{array}$ & Python (Keras) & $\begin{array}{l}\text { [30], [39], } \\
{[27]}\end{array}$ \\
\hline Caffe & $\begin{array}{l}\text { - Writing C++ / CUDA is } \\
\text { necessary for the new } \\
\text { GPU layers. } \\
\text { - Unsuitable for recurrent } \\
\text { networks } \\
\text { - Unmanageable for } \\
\text { large networks } \\
\text { (GoogLeNet, ResNet) } \\
\text { - Cannot be extended, a } \\
\text { bit of a hairball. } \\
\text { - Lack of commercial } \\
\text { supports. } \\
\text { - Decelerated } \\
\text { development. }\end{array}$ & $\begin{array}{l}\text { - Suitable for feed forward } \\
\text { networks \& image processing } \\
\text { - Suitable for fine-tuning the } \\
\text { current networks } \\
\text {-Easily train models } \\
\text { - Python interface is useful }\end{array}$ & $\begin{array}{l}\text { Linux, } \\
\text { macOS, } \\
\text { Windows }\end{array}$ & $\begin{array}{l}\text { Python, MATLAB, } \\
\text { C++ }\end{array}$ & [46] \\
\hline Matlab & & $\begin{array}{l}\text {-Support the ONNX model } \\
\text { format for using deep learning } \\
\text { frameworks } \\
\text { - Support MobileNet-v2, } \\
\text { ResNet-101, Inception-v3, } \\
\text { SqueezeNet, and Xception } \\
\text { - Import TensorFlow-Keras } \\
\text { models and generate CUDA } \\
\text { code }\end{array}$ & $\begin{array}{l}\text { Linux, } \\
\text { macOS, } \\
\text { Windows }\end{array}$ & MATLAB & $\begin{array}{l}\text { [41], [19], } \\
\text { [18], [31] }\end{array}$ \\
\hline
\end{tabular}

Page 21/34 
- Import DAG networks in the

Caffe model

\begin{tabular}{|c|c|c|c|c|c|}
\hline Python & $\begin{array}{l}\text {-Beginner's language } \\
\text { - Simplified learning } \\
\text {-Interpreted language } \\
\text {-Cross-platform } \\
\text { language } \\
\text {-Open and free source } \\
\text {-Object-oriented } \\
\text { language } \\
\text { - Large-scale libraries } \\
\text { - Integrated } \\
\text {-Data-bases Connectivity }\end{array}$ & $\begin{array}{l}\text {-Slower than C or C++ } \\
\text {-Not suitable for mobile } \\
\text { development } \\
\text {-Not good for memory- } \\
\text { intensive tasks } \\
\text {-Access to the database has } \\
\text { limitations }\end{array}$ & $\begin{array}{l}\text { Linux, } \\
\text { macOS, } \\
\text { Windows }\end{array}$ & Python & $\begin{array}{l}{[30],[26]} \\
{[42]}\end{array}$ \\
\hline $\begin{array}{l}\text { Weka \& } \\
\text { Java }\end{array}$ & & $\begin{array}{l}\text { - Support deep learning } \\
\text { graphical user interface (GUI) } \\
\text {-Support GPU } \\
\text { - GUI-based training [52] }\end{array}$ & $\begin{array}{l}\text { Linux, } \\
\text { macOS, } \\
\text { Windows }\end{array}$ & Weka & [43] \\
\hline $\mathrm{R}$ & $\begin{array}{l}\text { Support object-oriented } \\
\text { programming }\end{array}$ & $\begin{array}{l}\text { - Slow } \\
\text { - Single-threaded } \\
\text { - Very limited GPU support } \\
\text { - Not suitable for fast training }\end{array}$ & $\begin{array}{l}\text { Linux, } \\
\text { macOS, } \\
\text { Windows }\end{array}$ & RStudio & [29] \\
\hline
\end{tabular}

Table 11 describes the basic characteristics of the datasets used in the studied articles.

Table. 11. Type of Datasets

\begin{tabular}{|c|c|c|c|c|}
\hline $\begin{array}{l}\text { Using } \\
\text { in Ref }\end{array}$ & $\begin{array}{l}\text { Type } \\
\text { (homogeneous - } \\
\text { heterogeneous) }\end{array}$ & $\begin{array}{l}\text { The } \\
\text { number of } \\
\text { data }\end{array}$ & Description & $\begin{array}{l}\text { Name of } \\
\text { Dataset }\end{array}$ \\
\hline $\begin{array}{l}{[18],} \\
{[21],} \\
{[41]}\end{array}$ & Heterogeneous & $\begin{array}{l}\text { Not } \\
\text { specified }\end{array}$ & $\begin{array}{l}\text { speaker-independent corpus of over 7,000 utterances of } \\
\text { both connected and isolated digits }\end{array}$ & CUAVE [53] \\
\hline $\begin{array}{l}{[18],} \\
{[21]}\end{array}$ & Homogeneous & $\begin{array}{l}5,000 \text { train } \\
\text { data } \\
8,000 \text { test } \\
\text { data }\end{array}$ & image recognition dataset & $\begin{array}{l}\text { STL-10 } \\
{[54]}\end{array}$ \\
\hline$[21]$ & Heterogeneous & $\begin{array}{l}1,800 \\
\text { pieces }\end{array}$ & Subject from YouTube & $\begin{array}{l}\text { SNAE2 } \\
{[21]}\end{array}$ \\
\hline [25] & Heterogeneous & $4,000,000$ & $\begin{array}{l}\text { Diverse intrusions simulated in a military network } \\
\text { environment }\end{array}$ & $\begin{array}{l}\text { KDDCUP99 } \\
{[55]}\end{array}$ \\
\hline $\begin{array}{l}{[29]} \\
{[39]}\end{array}$ & Heterogeneous & $\begin{array}{l}125,973 \\
\text { train data } \\
22,544 \text { test } \\
\text { data }\end{array}$ & $\begin{array}{l}\text { The new version of the KDD data } \\
\text { The intrusion dataset }\end{array}$ & $\begin{array}{l}\text { NSL-KDD } \\
{[56]}\end{array}$ \\
\hline [29] & Homogeneous & $2,540,044$ & $\begin{array}{l}\text { Hybrid of authentic contemporary normal and attack } \\
\text { records }\end{array}$ & $\begin{array}{l}\text { NSW-NB15 } \\
{[57]}\end{array}$ \\
\hline , $[23]$ & Heterogeneous & 43930257 & The Heterogeneity Human Activity Recognition & HHAR [58] \\
\hline $\begin{array}{l}{[22],} \\
{[23]}\end{array}$ & Not specified & $\begin{array}{l}\text { Not } \\
\text { specified }\end{array}$ & User identification & UserlD [22] \\
\hline [20] & Heterogeneous & 20,000 & Web Image Dataset & $\begin{array}{l}\text { NUS-WIDE } \\
{[59]}\end{array}$ \\
\hline [20] & Heterogeneous & $\begin{array}{l}12,000 \\
\text { animal }\end{array}$ & Subset of animal & Animal-20 \\
\hline
\end{tabular}


Reply to RQ3: Which one of the deep learning models and platforms have been utilized more in the loT?

To answer this question, we examined the ideas expressed in the articles and the deep learning models used in them. Table 12 outlines the deep learning models used in the articles and categorizes these models into two categories: Generative and Discriminative. Then, in the Learning Model column, it specifies in which of the three modes (unsupervised, supervised, and semi-supervised) this model can be grouped. It also shows the type of input data in the Typical input data column and specifies the characteristics of each model.

Table. 12. Comparison of deep learning models 


\begin{tabular}{|c|c|c|c|c|c|c|c|c|}
\hline \multirow{2}{*}{$\begin{array}{l}\text { Used } \\
\text { in } \\
\text { references }\end{array}$} & \multirow[t]{2}{*}{ Characteristics } & \multirow{2}{*}{$\begin{array}{l}\text { Typical } \\
\text { input data }\end{array}$} & \multicolumn{3}{|c|}{ Learning Model } & \multicolumn{2}{|l|}{ Category } & \multirow[t]{2}{*}{ Mode } \\
\hline & & & $\begin{array}{l}\text { Semi- } \\
\text { supervised }\end{array}$ & $\begin{array}{l}\text { Un } \\
\text { supervised }\end{array}$ & Supervised & $\begin{array}{l}\text { Dis } \\
\text { criminative }\end{array}$ & Generative & \\
\hline $\begin{array}{l}\text { [18], [34], } \\
{[20],[29],} \\
\text { [41] }\end{array}$ & $\begin{array}{l}\text { - Reasonable } \\
\text { for include } \\
\text { extraction and } \\
\text { reduce } \\
\text { dimensionality } \\
\text { - The same } \\
\text { number of } \\
\text { output and } \\
\text { input units } \\
\text { Reconstruction } \\
\text { Ref the input } \\
\text { data by } \\
\text { outputs. } \\
\text { - Working with } \\
\text { unlabeled data }\end{array}$ & Diverse & & * & & & * & $\mathrm{AE}$ \\
\hline $\begin{array}{l}\text { [24], [27], } \\
\text { [28], [46], } \\
\text { [22] }\end{array}$ & $\begin{array}{l}\text {-Processes } \\
\text { groupings of } \\
\text { information } \\
\text { via inside } \\
\text { memory. } \\
\text { - Helpful in the } \\
\text { loT utilizations } \\
\text { with the time- } \\
\text { dependent } \\
\text { data }\end{array}$ & $\begin{array}{l}\text { Serial, } \\
\text { time- } \\
\text { series }\end{array}$ & & & * & * & & RNN \\
\hline $\begin{array}{l}\text { [31], [25], } \\
\text { [29] }\end{array}$ & $\begin{array}{l}\text {-Reasonable } \\
\text { for extracting } \\
\text { feature, } \\
\text { reducing } \\
\text { dimension } \\
\text {, and } \\
\text { classification } \\
\text { - Costly } \\
\text { training phase }\end{array}$ & Diverse & & * & * & & * & RBM \\
\hline [31] & $\begin{array}{l}\text { - Good for } \\
\text { hierarchical } \\
\text { features } \\
\text { extraction } \\
\text { - Greedy } \\
\text { training }\end{array}$ & Diverse & & * & * & & * & DBN \\
\hline $\begin{array}{l}\text { [33], [27], } \\
{[32],[28],} \\
{[47],[48]}\end{array}$ & $\begin{array}{l}\text {-proper } \\
\text { function } \\
\text { - Protected } \\
\text { access } \\
\text { memory cell }\end{array}$ & $\begin{array}{l}\text { Serial, } \\
\text { time- } \\
\text { series, } \\
\text { long time- } \\
\text { dependent } \\
\text { data }\end{array}$ & & & * & * & & LSTM \\
\hline $\begin{array}{l}\text { [40], [21], } \\
\text { [35], [24], } \\
{[37],[28],} \\
\text { [48] }\end{array}$ & $\begin{array}{l}\text { - Smaller } \\
\text { connection as } \\
\text { to DNNs. } \\
\text { - Requires a } \\
\text { big training }\end{array}$ & $\begin{array}{l}\text { Two-D } \\
\text { (image- } \\
\text { sound) }\end{array}$ & & & * & * & & CNN \\
\hline
\end{tabular}


data for

perceptible

tasks.

[8]

Diverse

VAE

- A group of

Auto-encoders

- Good for lack

of

labeled data

[22]

-Good for
noisy data
- Combined of
generator and
discriminator
networks

Diverse

*

$\star$

*

GAN

networks

Some of the deep learning structures that have been built and trained in basic deep learning models that are available to researchers are expressed in Table 13. These models can be used for similar applications using Transfer learning methods. The Deep Sense model is suitable for a variety of applications. The DeeploT model is a solution to efficient and appropriate energy. If you need high precision, the RDeepSense model can be a good option.

Table. 13. Other Deep Learning Models

\begin{tabular}{|lll|}
\hline Ref & Type & Name of Deep Model \\
\hline$[60],[40],[21]$ & CNN & AlexNet [61] \\
\hline$[60]$, [62] & CNN & SVHN [63] \\
\hline$[60]$ & DNN & Deep KWS \\
\hline$[60]$ & DNN & Deep Ear [64] \\
\hline$[22]$ & LSTM & DeeploT [65] \\
\hline$[22]$ & MLP & RDeepSense [66] \\
\hline$[22]$ & CNN, RNN & DeepSense \\
\hline$[46]$ & LSTM & VGGNet \\
\hline
\end{tabular}

In order to be trained, deep learning needs a proper hardware platform to be able to train the model at the right time with adequate speed. Various platforms have been used in the studied articles. Table 14 presents the platforms used in the articles if mentioned by the authors - as well as their basic characteristics.

Table. 14. Comparison of deep learning platforms 


\begin{tabular}{|c|c|c|}
\hline $\begin{array}{l}\text { Using } \\
\text { in } \\
\text { Ref }\end{array}$ & Description & $\begin{array}{l}\text { Name of the } \\
\text { platform }\end{array}$ \\
\hline [60] & $\begin{array}{l}\text { It has three processors and a } 2.3 \mathrm{GHz} 4 \text {-core CPU, a } 680 \mathrm{MHz} \text { Hexagon DSP and a } 330 \text { Adreno } \\
\text { GPU. }\end{array}$ & $\begin{array}{l}\text { Qualcomm } \\
\text { Snapdragon } \\
800\end{array}$ \\
\hline $\begin{array}{l}{[22],} \\
{[23]} \\
{[60]}\end{array}$ & $\begin{array}{l}\text { It contains a } 500 \mathrm{MHz} \text { dual-core Atom \Silvermont" } \\
\text { CPU helped by a } 100 \mathrm{MHz} \text { Quark processor. }\end{array}$ & Intel Edison \\
\hline $\begin{array}{l}{[60]} \\
{[40]}\end{array}$ & $\begin{array}{l}\text { The chip contains the Kepler 192-core GPU coupled with a } 2.3 \mathrm{GHz} \text { 4-core Cortex CPU and an extra } \\
\text { low power } 5^{\text {th }} \text { core (LPC) outlined for the energy efficiency. }\end{array}$ & $\begin{array}{l}\text { Nvidia } \\
\text { Tegra K1 }\end{array}$ \\
\hline [35] & $\begin{array}{l}\text { Nvidia's Tegra X2 ("Parker") characterizes the Nvidia's custom general-purpose ARMv8-compatible } \\
\text { core Denver } 2 \text { and the code-named Pascal graphics processing core with the GPGPU support. }\end{array}$ & $\begin{array}{l}\text { Nvidia } \\
\text { Tegra X2 }\end{array}$ \\
\hline [37] & $\begin{array}{l}\text { Nvidia's Tegra X1 ("Erista") characterizes } 4 \text { ARM Cortex-A57 cores, } 4 \text { ARM Cortex-A53 cores, and a } \\
\text { Maxwell-based graphics processing unit. }\end{array}$ & $\begin{array}{l}\text { Nvidia } \\
\text { Jetson TX1 }\end{array}$ \\
\hline [35] & $\begin{array}{l}\text { NVIDIA Jetson TX2 is one of the inserted system-on-modules (SoMs) with the dual-core NVIDIA } \\
\text { Denver2 + quad-core ARM Cortex-A57, 8GB 128-bit LPDDR4, which coordinates 256-core Pascal } \\
\text { GPU. }\end{array}$ & $\begin{array}{l}\text { Nvidia } \\
\text { Jetson TX2 }\end{array}$ \\
\hline \multirow[t]{2}{*}{ [28] } & $\begin{array}{l}\text { Nvidia Tesla is Nvidia's brand title for its items focusing on stream preparing or general-purpose } \\
\text { illustration handling units (GPGPU). }\end{array}$ & Nvidia Tesla \\
\hline & P100-PCI-E-16 GB GPU. & \\
\hline [27] & $\begin{array}{l}\text { Raspberry Pi could be a series of little single-board computers created within the Joined together } \\
\text { Kingdom by the Raspberry Pi Establishment to advance the instructing of essential computer } \\
\text { science in schools and creating nations. }\end{array}$ & $\begin{array}{l}\text { Raspberry } \\
\mathrm{Pi}\end{array}$ \\
\hline [40] & Intel Core i7 7770 CPU and NVIDIA Geforce GTX 1080. & \multirow{10}{*}{$\begin{array}{l}\text { Traditional } \\
\text { computer }\end{array}$} \\
\hline [21] & $\begin{array}{l}\text { The server has 10-core, } 20 \text {-thread, } 1.9 \mathrm{GHz} \text { Intel Xeon E7-4800 CPU, } 64 \text { GB RAM, and } 1 \text { TB hard } \\
\text { disk. }\end{array}$ & \\
\hline [19] & MacBook Pro has a $2.8 \mathrm{GHz}$ Intel Core i7 processor and 16GB RAM. & \\
\hline [18] & $\begin{array}{l}\text { Server with } 8 \text { cores and } 40 \text { threads, Intel Xeon E5-2620 CPU, a frequency of } 2.2 \mathrm{GHz} \text {, and } 64 \mathrm{~GB} \\
\text { RAM. }\end{array}$ & \\
\hline [37] & Zuluko includes 4 ARM v7 cores and 512 Mbytes of RAM. & \\
\hline [30] & Intel Core i7 2.00 GHz CPU, 4 GB RAM,Os Ubuntu 14.04. & \\
\hline [26] & A server with 8GB 1867MHz LPDDR3, 2GHz Intel Core i5, and 256G RAM. & \\
\hline [41] & The laptop has a $3.2 \mathrm{GHz}$ Core i7 CPU,8GB RAM, and 1T driver. & \\
\hline [48] & PC, Intel ${ }^{\circledR}$ Core $^{\mathrm{TM}}$ i7-6700K CPU, and an Nvidia GTX1070 GPU. & \\
\hline [42] & $\begin{array}{l}\text { Intel Core i7-6850K processor ( } 3.6 \mathrm{GHz}, 6 \text { cores), } 4 \text { GeForce } \\
\text { GTX1080Ti GPUs, and 64G RAM }\end{array}$ & \\
\hline
\end{tabular}

Reply to RQ4: What is the most important challenges of deep learning along with loT?

Having studied the articles in the loT and deep learning domains, we can categorized the challenges in this field into the following groups.

\section{Challenges associated with data and training model}

- Processing and analyzing large volumes of information [19].

- The existence of large dimensional heterogeneous data with a variety of expressions and excessive information and multimodal features [18] [20]. 
- The amount of information received from sensors on the loT [31] is very high. For training a DLM, there is a need for massive labeled data. Therefore, labeling large volumes of data and make them appropriate for training DLMs are difficult [22], [3]. The lack of labeled data for training the model [41] is a confront that still demands to be addressed.

- The industrial data with complex multimodal features constitutes another challenge in data analysis [16].

- IoT devices send a great deal of information to servers. The traffic generated by this information exchange is another challenge that can be mentioned in this area [42].

- Combining sensor data to extract latent (hidden) features [22] is also a challenge that can be addressed by deep learning.

- Overfitting [41]

\section{Resource Challenge}

- IoT devices are usually systems with low computing capabilities and limited memory and energy. Put differently, DL networks require a lot of resources to train their models [22]. Several ways can be presented to deal with this challenge.

- Presenting effective resource solutions for the uncertainty estimation problem [22].

- Presenting solutions to accurately estimate uncertainty in predicting results obtained from deep learning models [22].

\section{Network Challenge}

- On the loT, different networks are connected. The combination of heterogeneous networks and the connections between them is also one of the issues to be addressed [24] [20] [31] [29].

- The scope of available network size is limited.

\section{Cloud, fog, or edge spaces Challenge}

- Service latency [31]

- Task scheduling

- Back-haul bandwidth [31]

- Security mechanisms [39]

\section{Security and Privacy [28] [48]}

- Data injection, eavesdropping, man-in-the-middle threats [27].

- Absence of technical information or knowledge of the innate vulnerability by the owners of such devices [27].

- The poor safety and liveness properties [26]

Reply to RQ5: What are the open issues of deep learning along with loT?

Generally, three key characteristics were identified for extensive deep learning's application in recent times: the scale of required data, computational power, and the network structure. Therefore, deep learning with its high capability can play an important role in loT issues.

\section{- Processing large amounts of data in complex classifications}

The algorithm model of DL enjoys a far deeper structure than the two-layered structures of the old algorithms. In some cases, the number of the layers exceeds 100, enabling deep learning for processing enormous data in complicated categorizations. DL functions to a great extent in the same way as the human learning process, and it exhibits a layer-by-layer detection process. Deep learning helps to convert partial understanding to a deep general diagnosis, thus identifying the target subject.

\section{- Feature Extraction}


Deep learning does not require manual intervention; instead, it is dependent on a computer for extracting the respective characteristics. In this way, deep learning can extract the maximum number of possible characteristics from the intended subject; non-intuitive features so that their description among these characteristics would be infeasible or hard. Finally, if there are more characteristics, identification and detection would be more precise.

\section{- Real-time applications}

Deep learning would be utilized in real-time applications in a fog computational environment. Further, deep learning allows for more accurate decision-making for storing data on a cloud or fog space and reduces data transmission delay with proper management of data storage. It also allows for faster data storage and analysis in an appropriate environment.

\section{- The fog and blockchain technology}

The fog and blockchain technology, when combined with deep learning, help companies to gain more value from investing in the loT and overcome the past constraints to cover a wider range of the loT fields. Artificial intelligence and machine learning with deeper analysis immediately support data streams in more accurate decision-making. The fog computations make such systems scalable by expanding the cloud's ability to the network edge. Also, through processing and analysis near to the network edge, the fog computations help address latency, bandwidth, credit, and cost issues. On the other hand, the blockchain provides security for detecting loT transactions and will eliminate the need for a trusted central intermediary to connect the devices.

\section{- Different time-sensitive devices}

We can use deep learning distributed methods in different time-sensitive devices to reduce the high computations. We can be inspired by the quick and intelligent processing power of the human mind and offer more appropriate deep learning models for loT applications.

\section{Conclusion}

The present research presented findings of an SMS study in combination with the SLR on the loT with deep learning. Based on the main idea of the articles, they were divided into four sections. The subjects associated with the Network constituted the majority (i.e. 31\%, 10 articles) and the IEEE had the most publications in this area. The main utilized deep learning model in the reviewed articles was the CNN model, while Tensorflow was employed to implement more deep learning models in personal computers or proper platforms for deep learning. Among the reviewed articles, data challenges and deep model learning were more prominent. This study had some constraints. Only the titles of the articles were searched while extending the search domain, other articles could be found. Finally, the study focuses on English articles, and non-English articles were excluded.

\section{References}

1. Mehdi Mohammadi, Ala Al-Fuqaha, Sameh Sorour, Mohsen Guizani, "Deep Learning for loT Big Data and Streaming Analytics: A Survey," IEEE COMMUNICATIONS SURVEYS \& TUTORIALS, vol. 20, no. 4, pp. 2923 - 2960, 2018.

2. A. Alabaa, M. Othmana, I.A.T. Hashema, F. Alotaibib, "Internet of Things security: A survey," Journal of Network and Computer Applications, vol. 88, pp. 10-28, 2017.

3. Imran Makhdoom, Mehran Abolhasan, Haider Abbas, Wei Ni, "Blockchain's adoption in loT: The challenges, and a way forward," Journal of Network and Computer Applications, vol. 125, pp. 251-279, 2019.

4. Shadroo, A.M. Rahmani, "Systematic survey of big data and data mining in internet of things," Computer Networks, vol. 139, pp. 19-47, 2018.

5. Muhammet Usak, Milan Kubiatko, Muhammad Salman Shabbir, Olesya Viktorovna Dudnik, Kittisak Jermsittiparsert, Lila Rajabion, "Health care service delivery based on the Internet of things: A systematic and comprehensive study," International Journal of Communication Systems, vol. 32, no. 14, 2019. 
6. Huansheng Ning, Sha Hu, "Technology classification, industry, and education for Future Internet of Things," International Journal of Communication Systems, vol. 25, no. 9, p. 1230-1241, 2012.

7. Yanming Guo, Yu Liu, Ard Oerlemans, Songyang Lao, Song Wu, Michael S. Lew, "Deep learning for visual understanding: A review," Neurocomputing, vol. 187, p. 27-48, 2016.

8. Mehdi Mohammadi, Ala Al-Fuqaha, Mohsen Guizani, Jun-Seok Oh, "Semisupervised Deep Reinforcement Learning in Support of IoT and Smart City Services," IEEE Internet of Things Journal, vol. 5, no. 2, pp. 624 - 635, 2018.

9. Cruz-Benito, "Systematic Literature Review \& Mapping," Nov 2016. [Online]. Available: https://doi.org/10.5281/zenodo.165773.

10. Shojaiemehr, A.M. Rahmani, N.N. Qader, "Cloud computing service negotiation: A systematic review," Computer Standards \& Interfaces, 2017.

11. J. Ghomi, A.M. Rahmani, N.N. Qader, "Load-balancing algorithms in cloud computing: A survey," EJ Ghomi, AM Rahmani, NN Qader - Journal of Network and Computer Applications, 2017, vol. 88, pp. 50-71, 2017.

12. Engström, P. Runeson, "Software product line testing - A systematic mapping study," Information and Software Technology, vol. 53, no. 1, pp. 2-13, 2011.

13. Petersen, S. Vakkalanka, and L. Kuzniarz, "Guidelines for conducting systematic mapping studies in software engineering: An update," Information and Software Technology, vol. 64, pp. 1-18, 2015.

14. P. Breivold, I. Crnkovic, M. Larsson, "A systematic review of software architecture evolution research," Information and Software Technology, vol. 54, no. 1, pp. 16-40, 2012.

15. Patel, M. Taghavi, K. Bakhtiyari, J.C. Júnio, "An intrusion detection and prevention system in cloud computing: A systematic review," Journal of Network and Computer Applications, vol. 36, no. 1, pp. 25-41, 2013.

16. Tanwar, N. Kumar, Joel J.P.C. Rodrigues, "A systematic review on heterogeneous routing protocols for wireless sensor network," Journal of Network and Computer Applications, vol. 53, pp. 39-56, 2015.

17. Cocchia, "Smart and Digital City: A Systematic Literature Review," in Cocchia A. (2014) Smart and Digital City: A Systematic Literature Review. In Dameri R., Rosenthal-Sabroux C. (eds) Smart City., Progress in IS. Springer, 2014, pp. 13-43.

18. Wei Wang and Min Zhang, "Tensor Deep Learning Model for Heterogeneous Data Fusion in Internet of Things," IEEE Transactions on Emerging Topics in Computational Intelligence, pp. 1 - 10, 2018.

19. D. Liang, "Smart and Fast Data Processing for Deep Learning in Internet of Things: Less is More," IEEE Internet of Things Journal, 2018.

20. Fanyu Bu, Xin Wang, Bo Gao, "A multi-projection deep computation model for smart data in Internet of," Future Generation Computer Systems, vol. 93, pp. 68-76, 2019.

21. Peng Li, Zhikui Chen, Laurence T. Yang, Qingchen Zhang, and M. Jamal Deen, "Deep Convolutional Computation Model for Feature Learning on Big Data in Internet of Things," IEEE Transactions on Industrial Informatics, vol. 14, no. 2, pp. 790 - 798, 2018.

22. Shuochao Yao, Yiran Zhao, Huajie Shao, Chao Zhang, Aston Zhang, Shaohan Hu, Dongxin Liu, Shengzhong Liu, Lu Su, and Tarek Abdelzaher, "Deep Learning for the Internet of Things," Computer, vol. 51, no. 5, pp. 32-41, 2018.

23. Shuochao Yao, Yiran Zhao, Huajie Shao, Chao Zhang, Aston Zhang, Shaohan Hu, Dongxin Liu, Shengzhong Liu, Lu Su, and Tarek Abdelzaher, "SenseGAN: Enabling Deep Learning for Internet of Things with a Semi-Supervised Framework," Proceedings of the ACM on Interactive, Mobile, Wearable and Ubiquitous Technologies, vol. 2, no. 3, 2018.

24. Khelifi; S. Luo; B. Nour; A. Sellami; H. Moungla, "Bringing Deep Learning at the Edge of Information-Centric Internet of Things," IEEE Communications Letters, vol. 23, no. 1, pp. 52-55, 2019.

25. Dawoud, S. Shahristani, Ch. Raun, "Deep learning and software-defined networks: Towards secure loT architecture," Internet of Things, Vols. 3-4, pp. 82-89, 2018.

26. Qiu, F. R. Yu, H. Yao, C. Jiang, F. Xu, and C. Zhao, "Blockchain-Based Software-Defined Industrial Internet of Things: A Dueling Deep Q-Learning Approach," Internet of Things Journal, vol. 6, no. 3, pp. 4627-4639, 2019. 
27. D. McDermott, F. Majdani, and A. V. Petrovski, "Botnet Detection in the Internet of Things using Deep Learning Approaches," in International Joint Conference on Neural Networks (IJCNN), Rio de Janeiro, 2018.

28. Jafari, O. Omotere, D. Adesina, H. Wu, and L. Qian, "loT Devices Fingerprinting Using Deep Learning," in MILCOM 2018 2018 IEEE Military Communications Conference (MILCOM), Los Angeles, CA, 2018.

29. Muna AL-Hawawreh, Nour Moustafa, Elena Sitnikova, "Identification of malicious activities in industrial internet of things based on deep learning models," Journal of Information Security and Applications, vol. 41, pp. 1-11, 2018.

30. I. Ayadi, F. Z. Saadaoui, A. Maizatc, M. Ouzzif, and C. Mahmoudi, "Deep Learning for Packet Forwarding with an Application for Real-Time loT," in 2018 International Conference on Selected Topics in Mobile and Wireless Networking (MoWNeT), Tangier, 2018.

31. Hye-Young Kim, Jong-Min Kim, "A load balancing scheme based on deep-learning in loT," Cluster Computing, vol. 20, no. 1, p. 873-878, 2017.

32. Ferdowsi, W. Saad, "Deep Learning-Based Dynamic Watermarking for Secure Signal Authentication in the Internet of Things," in 2018 IEEE International Conference on Communications (ICC), Kansas City, MO, USA, 2018.

33. Ferdowsi and W. Saad, "Deep Learning for Signal Authentication and Security in Massive Internet-of-Things Systems," IEEE Transactions on Communications, vol. 63, no. 2, pp. 1371-1387, 2019.

34. Zhu, Y. Song, D. Jiang, and H. Song, "A New Deep-Q-Learning-Based Transmission Scheduling Mechanism for the Cognitive Internet of Things," Internet of Things Journal, vol. 5, no. 4, pp. 2375-2385, 2018.

35. Qi and C. Liu, "Enabling Deep Learning on IoT Edge: Approaches and Evaluation," in 2018 IEEE/ACM Symposium on Edge Computing (SEC), Seattle, WA, 2018.

36. Wei, F. R. Yu, M. Song, and Z. Han, "Joint Optimization of Caching, Computing, and Radio Resources for Fog-Enabled loT Using Natural Actor-Critic Deep Reinforcement Learning," IEEE Internet of Things Journal, vol. 6, no. 2, pp. 2061-2073, 2019.

37. Tang, D. Sun, S. Liu and J. Gaudiot, "Enabling Deep Learning on loT Devices," Computer, vol. 50, no. 10, pp. 92-96, 2017.

38. Lyu, J. C. Bezdek, X. He and J. Jin, "Fog-Embedded Deep Learning for the Internet of Things," IEEE Transactions on Industrial Informatics, vol. 15, no. 7, pp. 4206-4215, 2019.

39. A. Diro, N. Chilamkurti, "Distributed attack detection scheme using deep learning approach for Internet of Things," Future Generation Computer Systems, vol. 82, pp. 761-768, 2018.

40. Li, K. Ota, and M. Dong, "Learning loT in Edge: Deep Learning for the Internet of Things with Edge Computing," IEEE Network, vol. 32, no. 1, pp. 96-101, 2018.

41. Zhang, L. T. Yang, Z. Chen, P. Li, and F. Bu, "An Adaptive Dropout Deep Computation Model for Industrial loT Big Data Learning With Crowdsourcing to Cloud Computing," IEEE Transactions on Industrial Informatics, vol. 15, no. 4, pp. 2330 2337, 2019.

42. Zhu, Y. Cao, X. Wei, W. Wang, T. Jiang, and S. Jin, "Caching Transient Data for Internet of Things: A Deep Reinforcement Learning Approach," IEEE Internet of Things Journal, vol. 6, no. 2, pp. 2074-2083, 2019.

43. Sundaravadivel, K. Kesavan, L. Kesavan, S. P. Mohanty, and E. Kougianos, "Smart-Log: A Deep-Learning Based Automated Nutrition Monitoring System in the loT," IEEE Transactions on Consumer Electronics, vol. 64, no. 3, pp. 390-398, 2018.

44. Sajith Vellappally, Abdulaziz A. Al Kheraif, Sukumaran Anil, Ashraf A. Wahba, "loT medical tooth mounted sensor for monitoring teeth and food level using bacterial optimization along with adaptive deep learning neural network," Measurement, vol. 135, pp. 672-677, 2019.

45. Chenhui Yao, Shuodong Wu, Zhuo Liu, Peng Li, "A deep learning model for predicting chemical composition of gallstones with big data in medical Internet of Things," Future Generation Computer Systems, vol. 94, pp. 140-147, 2019.

46. Sun, L. Xu, L. Li, B. Xu, C. Yin, and H. Cai, "Deep Learning Based Image Cognition Platform for loT Applications," in 2018 IEEE 15th International Conference on e-Business Engineering (ICEBE), Xi'an, 2018.

47. Aruul Mozhi Varman, A. R. Baskaran, S. Aravindh and E. Prabhu, "Deep Learning and loT for Smart Agriculture Using WSN," in 2017 IEEE International Conference on Computational Intelligence and Computing Research (ICCIC), Coimbatore, 2017. 
48. Xuyu Wang, Xiangyu Wang, Shiwen Mao, "RF Sensing in the Internet of Things: A General Deep Learning Framework," IEEE Communications Magazine, vol. 56, no. 9, pp. 62 - 67, 2018.

49. Kharkovyna, "Top 10 Best Deep Learning Frameworks in 2019," 3 Jun 2019. [Online]. Available: https://towardsdatascience.com/top-10-best-deep-learning-frameworks-in-2019-5ccb90ea6de. [Accessed 24 July 2019 ].

50. "Comparison of deep-learning software," [Online]. Available: https://en.wikipedia.org/wiki/Comparison_of_deeplearning_software. [Accessed 24 July 2019].

51. Mitul Makadia, "Dzone," 29 March 2018. [Online]. Available: https://en.wikipedia.org/wiki/Comparison_of_deeplearning_software. [Accessed 24 July 2019].

52. Steven Lang, Felipe Bravo-Marquez, Christopher Beckham, Mark Hall, Eibe Frank, "WekaDeeplearning4j: A deep learning package for Weka based on Deeplearning4j," Knowledge-Based Systems, vol. 178, pp. 48-50, 2019.

53. K. Patterson, S. Gurbuz, Z. Tufekci, and J. N. Gowdy, "CUAVE: A new audio-visual database for multimodal human-computer interface research," in 2002 IEEE International Conference on Acoustics, Speech, and Signal Processing, Orlando, FL, 2002.

54. Adam Coates, Honglak Lee, Andrew Y. Ng, "An Analysis of Single-Layer Networks in Unsupervised Feature Learning," AISTATS, 2011.

55. Saharon Rosset, Aron Inger, "KDD-cup 99: knowledge discovery in a charitable organization's donor database," SIGKDD Explor. Newsl., vol. 1, no. 2, pp. 85-90, 2000.

56. Tavallaee, E. Bagheri, W. Lu, and A. Ghorbani, "A Detailed Analysis of the KDD CUP 99 Data Set," Second IEEE Symposium on Computational Intelligence for Security and Defense Applications (CISDA), 2009.

57. Moustafa, J. Slay, and G. Creech, "Novel Geometric Area Analysis Technique for Anomaly Detection using Trapezoidal Area Estimation on Large-Scale Networks," IEEE Transactions on Big Data, 2017.

58. Allan Stisen, Henrik Blunck, Sourav Bhattacharya, Thor Siiger Prentow, Mikkel Baun Kjærgaard, Anind Dey, Tobias Sonne, and Mads Møller Jensen, "Smart Devices are Different: Assessing and Mitigating Mobile Sensing Heterogeneities for Activity Recognition," in 13th ACM Conference on Embedded Networked Sensor Systems (SenSys 2015), Seoul, Korea, 2015.

59. Tat-Seng Chua, Jinhui Tang, Richang Hong, Haojie Li, Zhiping Luo, and Yan-Tao Zheng, "NUS-WIDE: A Real-World Web Image Database from National University of Singapore," in ACM International Conference on Image and Video Retrieval, Greece, 2009.

60. Nicholas D. Lane, Sourav Bhattacharya, Petko Georgiev, Claudio Forlivesi, Fahim Kawsar, "An Early Resource Characterization of Deep Learning on Wearables, Smartphones, and Internet-of-Things Devices," in Proceedings of the 2015 International Workshop on Internet of Things towards Applications, Seoul, South Korea, 2015.

61. Krizhevsky, A., Sutskever, I., Hinton G.E., "Image net classification with deep convolutional neural networks," in Advances in Neural Information Processing Systems, 2012.

62. D. Lane et al., "DeepX: A Software Accelerator for Low-Power Deep Learning Inference on Mobile Devices," in 15th ACM/IEEE International Conference on Information Processing in Sensor Networks (IPSN), Vienna, 2016.

63. Netzer, et al., "Reading Digits in Natural Images with Unsupervised Feature Learning.," in NIPS workshop on deep learning and unsupervised feature learning, 2011.

64. Lane, P. Georgiev, L. Qendro, "DeepEar: Robust Smartphone Audio Sensing In Unconstrained Acoustic Environments Using Deep Learning," in UbiComp '15, 2015.

65. Yao, Y. Zhao, A. Zhang, L. Su, and T. Abdelzaher, "DeeploT: Compressing deep neural network structures for sensing systems with a compressor-critic framework," in 15th ACM Conf. Embedded Netw. Sensor Syst. (SenSys), 2017.

66. Yao, Y. Zhao, H. Shao, A. Zhang, C. Zhang, S. Li, and T. Abdelzaher, "Rdeepsense: Reliable deep mobile computing models with uncertainty estimations," in Proceedings of the ACM on Interactive, Mobile, Wearable and Ubiquitous Technologies, 2018.

67. "ACM," 201 2021. [Online]. Available: http://portal.acm.org.

68. "Institute of Electrical and Electronics Engineers (IEEE)," 201 2021. [Online]. Available:

https://ieeexplore.ieee.org/.

Page $31 / 34$ 
69. "Elsevier," 201 2021. [Online]. Available: http://www.elsevier.com.

70. "Springer," 201 2021. [Online]. Available: https://www.springer.com/gp.

71. "Wiley Online Library," 201 2021. [Online]. Available: https://onlinelibrary.wiley.com/.

\section{Figures}

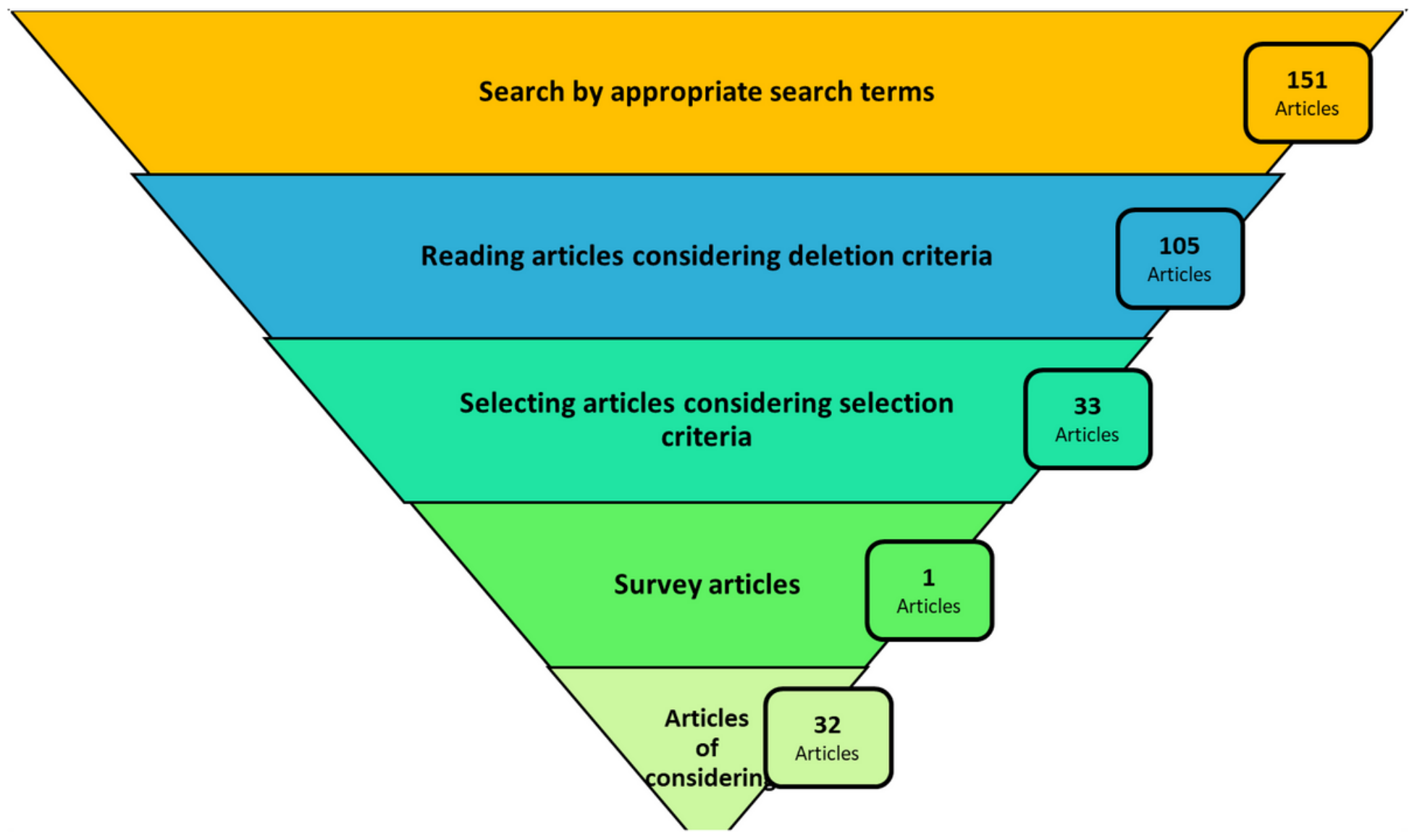

Figure 1

The article selection process in the study 


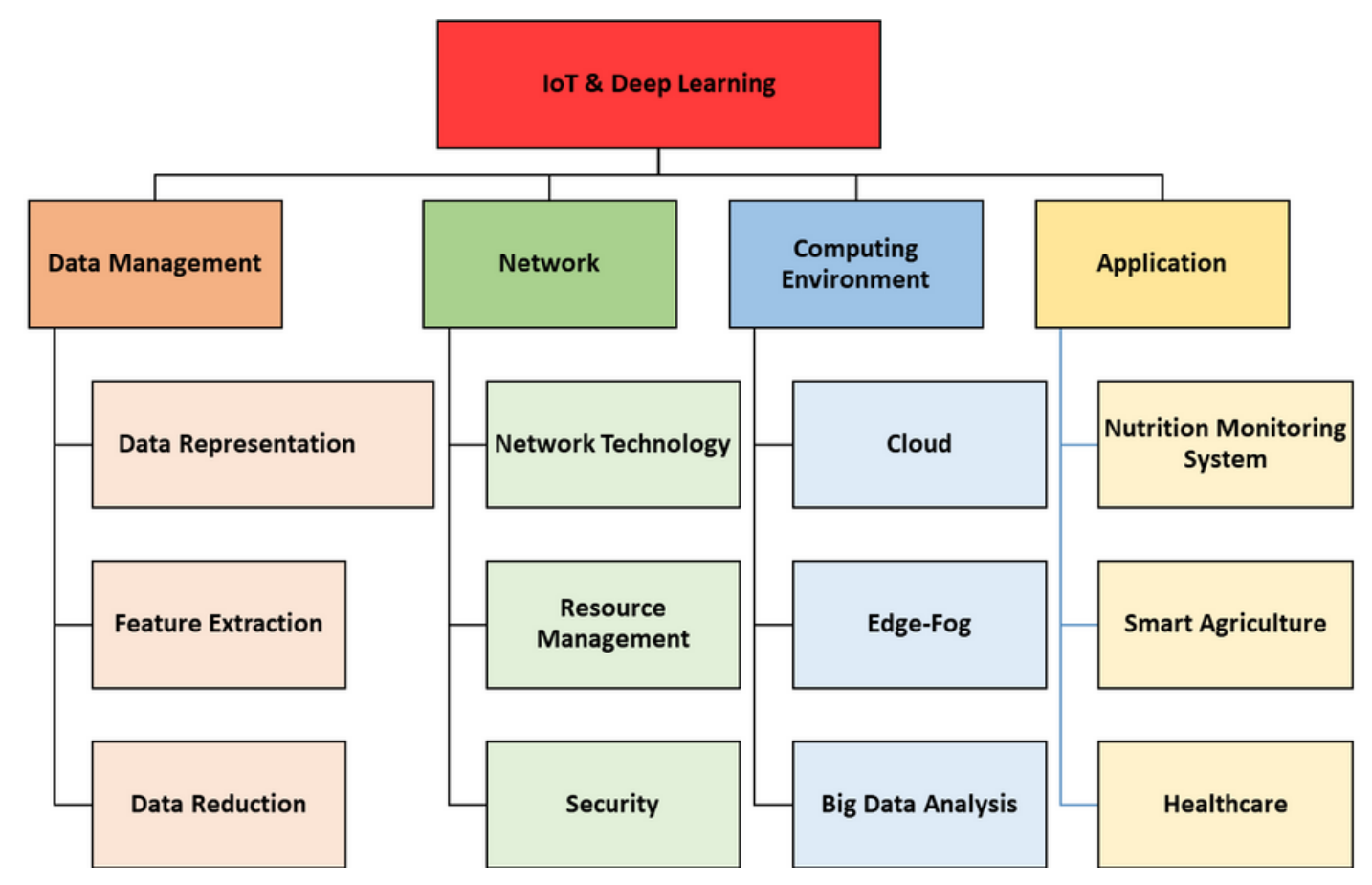

Figure 2

The taxonomy based on the Idea in loT \& Deep Learning

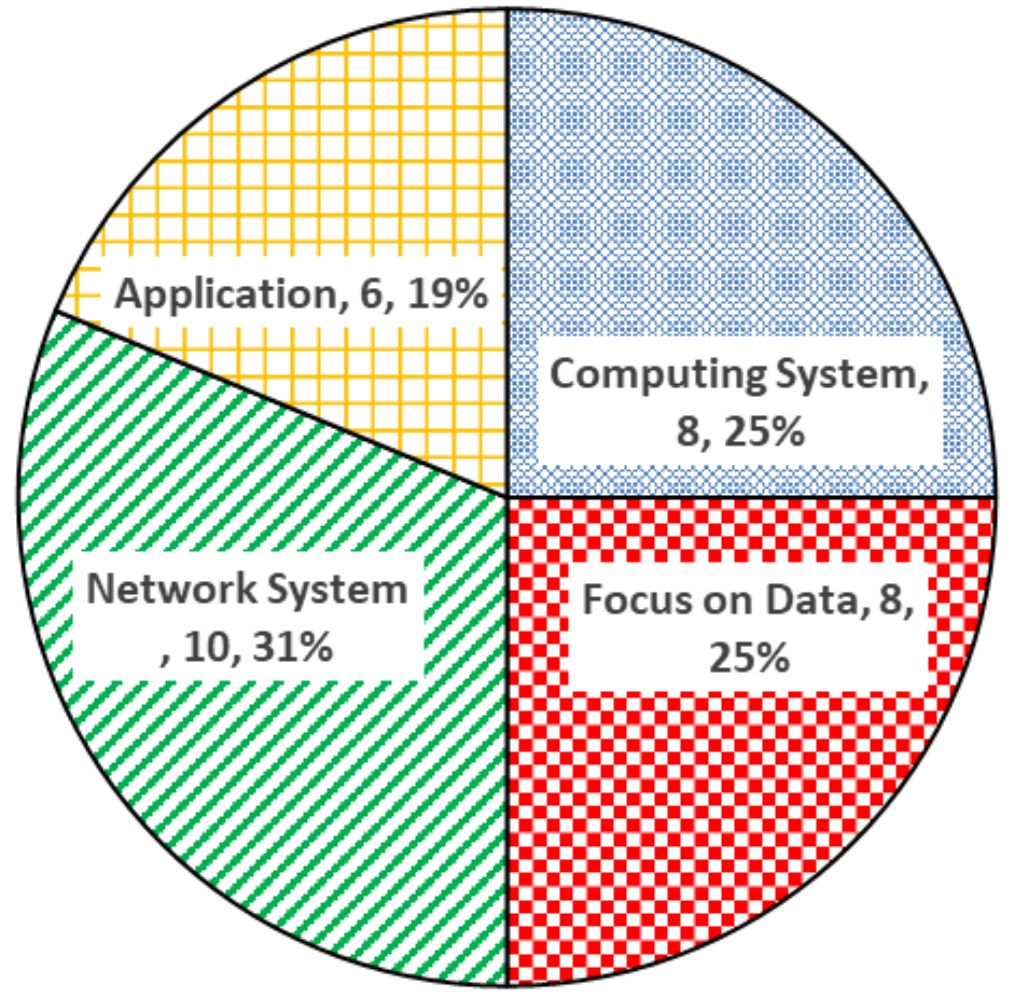

Figure 3

Dispersion rate of publications by Categories 


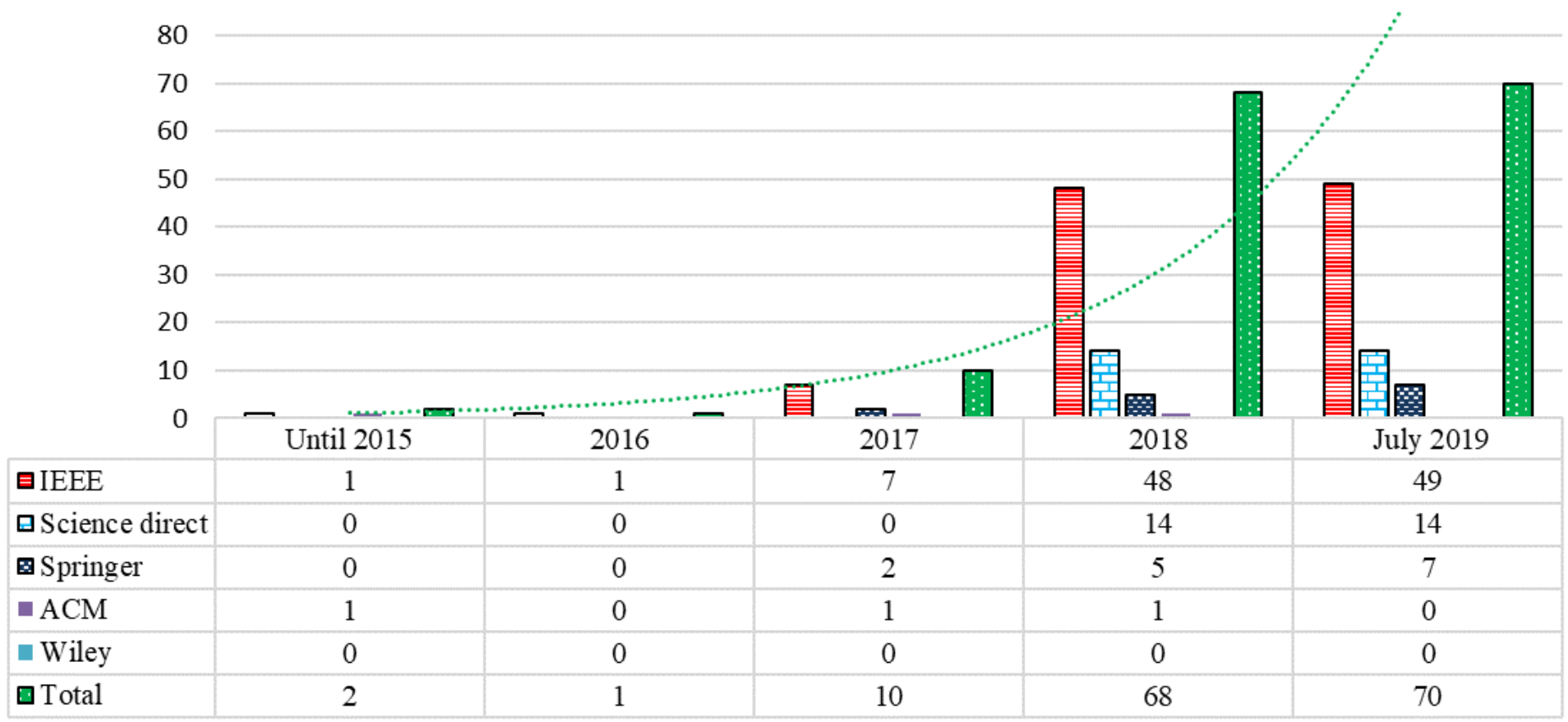

Figure 4

The number of all articles by years and publishers 